\title{
29. MILANKOVITCH CYCLES AND NONLINEAR RESPONSE IN THE QUATERNARY RECORD IN THE ATLANTIC SECTOR OF THE SOUTHERN OCEANS1
}

\author{
D. C. Nobes, ${ }^{2}$ S. F. Bloomer, ${ }^{3}$ J. Mienert,${ }^{4}$ and F. Westall ${ }^{5}$
}

\begin{abstract}
Previous studies of deep-sea sediment cores have found evidence for Milankovitch cycles, climatic cyclicity due to the periodicity of the Earth's orbital parameters. Many of the cores recovered on Leg 114 of the Ocean Drilling Program showed outward signs of cyclicity, especially at Site 704. We have analyzed the GRAPE density, carbonate content, and magnetic susceptibility using both standard and nonstandard spectral analysis techniques. One of the nonstandard techniques used was the Lomb-Scargle spectral estimation method, which is designed for unequally spaced data and which yields as part of the process the statistical significance of any observed spectral peaks. Pairs of spectra were compared for statistical similarity using the Kolmogorov-Smirnov method. All of the data sets contain some spectral peaks, including both the expected Milankovitch cycles as well as other peaks. Upon further investigation, we have found that the other peaks could be explained as the nonlinear climate system response to the Milankovitch orbital forcing functions, because the extra peaks appear to be simple linear combinations, harmonics and subharmonics of the Milankovitch peaks. At Site 704, there is a marked change in the response at the Brunhes/Matuyama boundary (0.73 Ma B.P.) from strong long-period cyclicity in the Brunhes to more prevalent shorter period cyclicity in the Matuyama.
\end{abstract}

\section{INTRODUCTION}

The hydrosphere of the Earth is complex and inherently nonlinear. The Navier-Stokes equations and the associated thermodynamic equations form a coupled highly nonlinear set of governing equations for atmospheric and oceanic flow. The climate of the Earth represents a long-term average of the parameters of the nonlinear system and thus should also exhibit nonlinearity. Nonetheless, numerous researchers have sought simple (linear) mechanisms to explain major climatic variations.

The most prominent such mechanism recently proposed for driving climatic variations has been the effect of the periodicity in the Earth's orbital parameters, Milankovitch cycles (see, for example, Berger et al., 1984). The analysis of deep-sea drill core and logging data has naturally expanded to include spectral analysis for the purposes of identifying Milankovitch cycle peaks, and numerous papers have found evidence for such peaks (see Berger et al. 1984; Ruddiman et al., 1986).

In many cases extraneous peaks have been found, for example, by Pestiaux and Berger (1984) and Ruddiman et al., (1986). Figure 1 (from Borehole Research Group, 1986) shows results from Ocean Drilling Program (ODP) Site 646; Milankovitch peaks are identified at $19,000-23,000,41,000,95,000$, and $410,000 \mathrm{yr}$. The presence of other peaks, however, can be explained as linear combinations of the main peaks. We

\footnotetext{
${ }^{1}$ Ciesielski, P. F., Kristoffersen, Y., et al., 1991. Proc, ODP, Sci. Results, 114: College Station, TX (Ocean Drilling Program).

2 Department of Earth Sciences, Department of Physics, and Quaternary Sciences Institute, University of Waterloo, Waterloo, Ontario, Canada N2L $3 \mathrm{Gl}$.

${ }^{3}$ Department of Physics and Quaternary Sciences Institute, University of Waterloo, Waterloo, Ontario, Canada N2L 3G1.

4 GEOMAR, Forschungszentrum der Christian-Albrechts-Universität zu Kiel, D-2300 Kiel, FRG.

5 Alfred Wegener Institut für Polar und Meeresforschung, Postfach 120161, D-2850 Bremerhaven (Present address: Université de Nantes, Laboratoire de Sédimentologie Sciences de la Terre, 2 Rue de la Houssiniere, 44072 Nantes Cedex, France).
}

believe that these extraneous peaks are evidence for the nonlinear nature of the climatic system (Bloomer and Nobes, 1989; Bloomer, 1989).

The prominent spectral power at $100,000 \mathrm{yr}$ found in most ocean core and logging data spectra is another compelling piece of evidence for the nonlinear nature of climatic response. Because there is no primary power at the eccentricity $(100,000 \mathrm{yr})$ cycle in the expansions of theoretical solar insolation (the eccentricity term acts only to modulate the precessional cycles), the high power in paleoclimatic spectra associated with the 100,000 -yr cycle has been attributed to the effect of ice sheets (Pollard, 1982; Le Treut and Ghil, 1983) or some other nonlinear mechanism.

To demonstrate how 100,000 -yr power can arise in paleoclimatic spectra, Wigley (1976) considered an amplitudemodulated periodic signal of the form

$$
F(t)=\left(1+\beta \sin \left(2 f_{2} t\right)\right) \sin \left(2 f_{1} t\right),
$$

where $f_{1}$ is the frequency of the basic signal and $f_{2}$ is the modulator frequency. This is analogous to the insolation signal, where the 100,000 -yr cycle acts as a modulator of the precessional cycles at 23,000 and $19,000 \mathrm{yr}$. In the plot of $F(t)$ in Figure $2 \mathrm{~A}, f_{1}=1 / 20,000$ cycles $/ \mathrm{yr}, f_{2}=1 / 100,000$ cycles $/ \mathrm{yr}$, and $\beta=0.4$. Spectral analysis of this signal yields a major peak at $f_{1}$, minor peaks $f_{1} \pm f_{2}(16,000$ and $25,000 \mathrm{yr})$, and no peak at the modulator frequency, $f_{2}$ (Fig. 2B). If the output is related to the input by the simple nonlinear response model

$$
Z(t)=(F(t))^{2},
$$

the spectrum of $Z(t)$ has a dominant peak at the modulator frequency, with a series of peaks centered at $2 f_{1}(10,000 \mathrm{yr})$ and a peak at $2 f_{2}(50,000 \mathrm{yr})$ (Fig. 2C). This demonstrates how primary output power can arise from relatively minor input power and how combination tones can arise.

We have analyzed data from sediment cores of Quaternary age recovered on ODP Leg 114 . The Leg 114 sites form a transect across the South Atlantic (Figs. 3 and 4; Shipboard 


\section{POROSITY FROM \\ RESISTIVITY LOG}

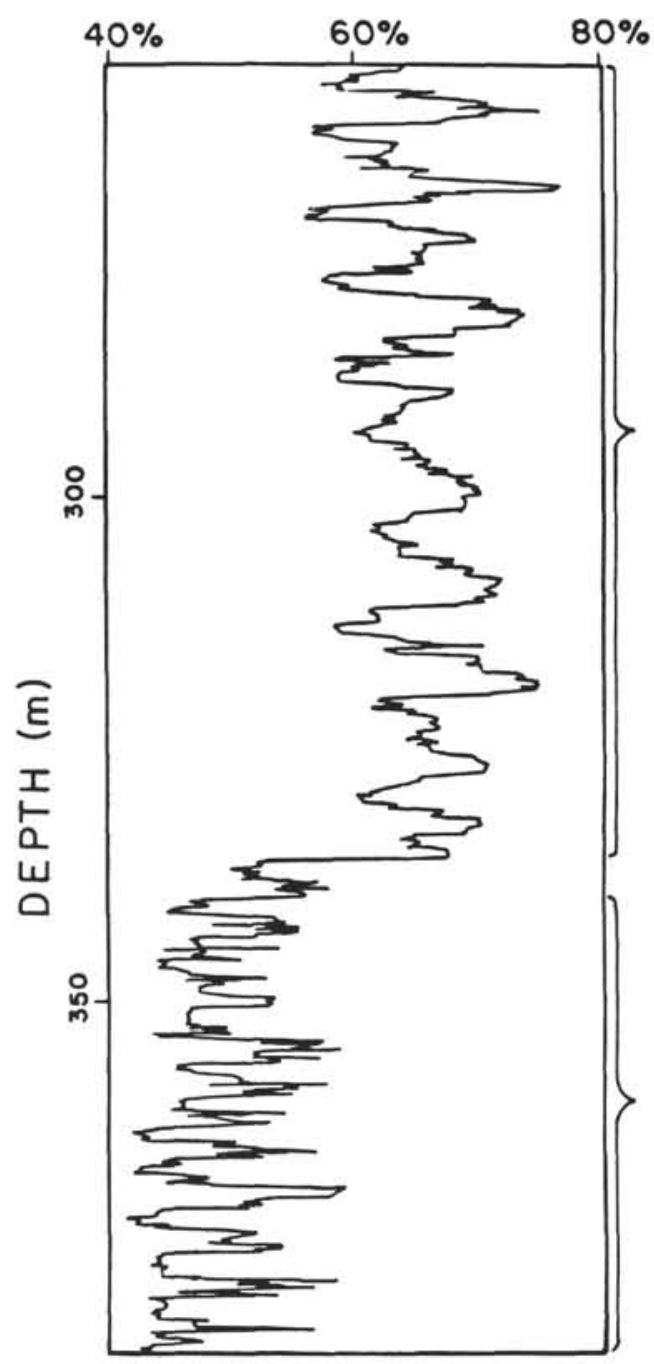

AMPLITUDE SPECTRA

OF POROSITY LOG

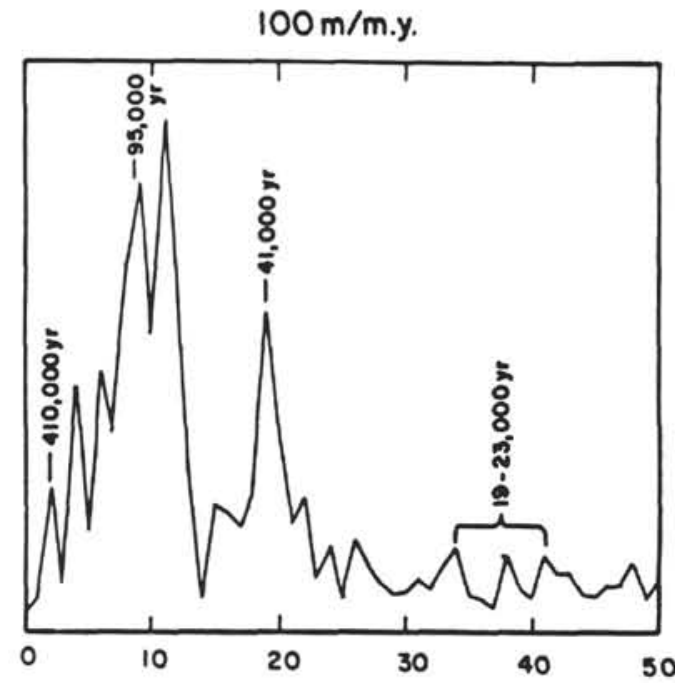

$52 \mathrm{~m} / \mathrm{m} . \mathrm{y}$.

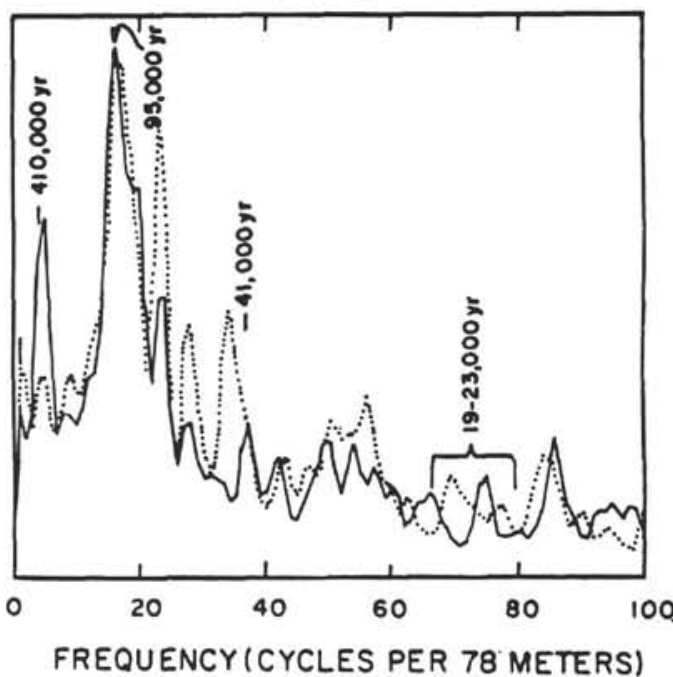

Figure 1. Spectral analysis of the resistivity-derived porosity from ODP Leg 105 Site 646 for segments with different rates of sedimentation. Note the presence of peaks between 95,000 and $410,000 \mathrm{yr}$ and between 41,000 and 95,000 yr. (From Borehole Research Group, 1986.)

Scientific Party, 1988b). Only Sites 699, 701, and 704 contained significant amounts of sediment of Quaternary age, composed primarily of siliceous and some calcareous ooze (Fig. 4). In most cases we find some Milankovitch peaks, but we also find additional spectral peaks that appear as the sums, differences, harmonics, and subharmonics of Milankovitch peaks, which would be expected for the response of a nonlinear system.

\section{DATA}

Core recovered at Site 704 on the Meteor Rise shows distinct and apparently cyclic color changes as the sediment oscillates between siliceous and carbonaceous oozes. Such "bedding" was examined before for cyclicity (e.g., Arthur et al., 1984; Dean and Gardner, 1984). The cyclicity in Core 114-704A-7H (Fig. 5A), for example, is present in the physical-property data as well, as illustrated in the gamma- ray attenuation porosity evaluator (GRAPE) density record (Fig. 5B). The purpose of our study, which is ongoing, was therefore to examine the physical-property data, especially the GRAPE density. For comparison we also analyzed the carbonate content and magnetic susceptibility, which were sampled at regular intervals, especially at Site 704 .

Before we discuss the spectral analysis techniques that were used in our study, we wish to discuss the properties of the data sets used here. For example, many researchers mistrust the GRAPE data, at times perhaps with some justification. We will thus deal briefly with each data set.

\section{GRAPE Density}

The GRAPE density is determined by measuring the attenuation of a calibrated gamma-ray source upon passage through a core of unknown density. The density is calculated as described 
Jy Boyce (1976), using the Compton mass attenuation coefficient or quartz, which is approximately valid for the siliceous and zarbonaceous oozes generally recovered on Leg 114. For filled iners of advanced hydraulic piston cores, the density compares avorably with the (laboratory-measured) wet-bulk density (Fig. ). The wet-bulk density, in turn, compares well with the density ogging data (Nobes et al., this volume).

We are interested less in the absolute density values than we are in the density variations, and, as shown in Figure 5, the Jensity excursions in the GRAPE densities for Core 114704A-7H can be directly correlated with the distinct color shanges in the core photograph. In the absence of terrigenous material, the density variations can thus be correlated with shanges in the biota, that is, changes from primarily diatoms to primarily nannofossils, that are in turn associated with changes in the climatic conditions. At Site 704, for example, the Polar Front migrates to the north and south across the Meteor Rise as the climate migrates from glacial to interglacial periods. The GRAPE density is recorded every centimeter and could be used as a high-resolution paleoclimatic record, as the density variations reflect the changes in the biota. The terrigenous component is negligible at Sites 699 and 704 and is a small component at Site 701 .

\section{Carbonate Content}

The carbonate content reflects to a large extent the deposition of the remains of calcareous biota. In the Quaternary section of Hole 704A, the portions with low carbonate content are high in biogenic silica, that is, rich in diatomaceous remains. Thus, the carbonate content reflects the changes in the biota associated with the migration of the Polar Front across the Meteor Rise. Cyclicity in the carbonate content has been analyzed for other locations (Arthur et al., 1984; Dean and Gardner, 1984).

The procedure for determination of carbonate content has been outlined previously (Shipboard Scientific Party, 1988a). The carbonate content was sampled only as frequently as the index properties, approximately once per section or less, except in Hole 704A, where the carbonate content was sampled about every $30 \mathrm{~cm}$ in the Quaternary section, and in a part of Hole 704B that overlaps a section of poor core recovery in Hole 704A. The value recorded represents an average over a depth range of approximately $2 \mathrm{~cm}$. Because of the sparse sampling in the other holes, spectral analysis was performed only on the Hole 704A carbonate content data and on the Site 704 composite section.

\section{Magnetic Susceptibility}

Magnetic susceptibility measurements taken every $10 \mathrm{~cm}$ using the Bartington whole-core and discrete sample sensors (Shipboard Scientific Party, 1988a) represent an average over a depth interval of $2-3 \mathrm{~cm}$. The magnetic susceptibility responds to variations in the amount of magnetic minerals present, and in areas adjacent to land it can be related to the terrigenous component. As such, the response of the magnetic susceptibility is not as clearly related to climatic variability as the GRAPE and carbonate records, though studies of loess in marine sediments indicate that the variability of wind direction and magnitude has an effect (Hovan et al., 1989). However, spectral analysis of magnetic susceptibility data has been used for the study of cyclicity (deMenocal and ODP Leg 117 Shipboard Scientific Party, 1988), and the regular, relatively dense sampling provides a data set that lends itself to such analyses.

\section{Composite 704 Section}

Because Holes 704A and 704B are only approximately $10 \mathrm{~m}$ apart, the two holes should be stratigraphically identical. By splicing the two data sets together, we can replace intervals that are obviously disturbed, such as from 5 to $15 \mathrm{~m}$ below seafloor (mbsf) at Hole $704 \mathrm{~A}$, and produce a continuously sampled record for Site 704. The splicing procedure and composite chronology of Froelich et al. (this volume), which are based on common color changes and other markers, were used in this study to form a composite Site 704 time series.

\section{Preprocessing}

Before any power spectra were computed, all of the data discussed in the preceding were preprocessed. Any data collected from highly fractured or disturbed core were eliminated, as they are unreliable. The mean and any linear trends were removed, as we are interested in only relative and not absolute values. For the most part, there was no linear trend for the Quaternary data. The data were then normalized by converting the readings to units of standard deviation. That is, we computed the standard deviation of the residual data set (mean and trend removed) and divided the residual by the standard deviation. This produced data sets with zero mean and unit variance.

\section{Depth-to-Age Conversion}

To convert the data to a time series, a mean depth-to-age conversion was constructed using the biostratigraphic and paleomagnetic age picks for each site in turn to construct a mean depth-to-age conversion (Shipboard Scientific Party, $1988 \mathrm{c}, 1988 \mathrm{~d}, 1988 \mathrm{e}$ ), for which the chronology was used to convert the data to a time series. Data for $\delta^{18} \mathrm{O}$ were not available at the time of the study for comparison with the event chronology previously established for globally averaged $\delta^{18} \mathrm{O}$ data (Imbrie et al., 1984). Commonly two or more age picks were in conflict. For instance, two age picks may span different age ranges but have overlapping depth ranges and vice versa. To resolve this difficulty, the following criteria were used, in order of preference: (1) age picks with the smallest depth range (best depth resolution) and (2) paleomagnetic before biostratigraphic age picks. The resulting normalized time series were processed using the spectral analysis techniques described in the following section. The depth-toage conversion is the weakest part of any study such as the one carried out here, because we cannot know if the age picks are complete or if short-term changes in the sedimentation rate occurred. As we will show, evolutive spectral analysis can be used as an aid in the identification of such gaps in the depth-to-age conversion.

The age-depth picks have error bounds, which thus yield maximum and minimum ages for each depth and maximum and minimum sedimentation rates for each interval. There is in turn an error bound associated with the positions of spectral peaks due to uncertainty in the sedimentation rates. We have investigated the effects of using maximum and minimum sedimentation rates, in essence expanding or compressing the time scale, on the spectral peaks. As the sedimentation rate increases or decreases by some multiplicative factor (e.g., 1.1 or 0.9 times the calculated rate), then the periods of the peaks shift by the same factor. On a logarithmic period scale, this is the same as shifting all of the peaks over some constant distance, because multiplication becomes addition in the logarithmic domain. The peaks observed in the individual periodograms are, in general, resolved as separate peaks. In other words, the error bounds on the position 
D. C. NOBES ET AL.
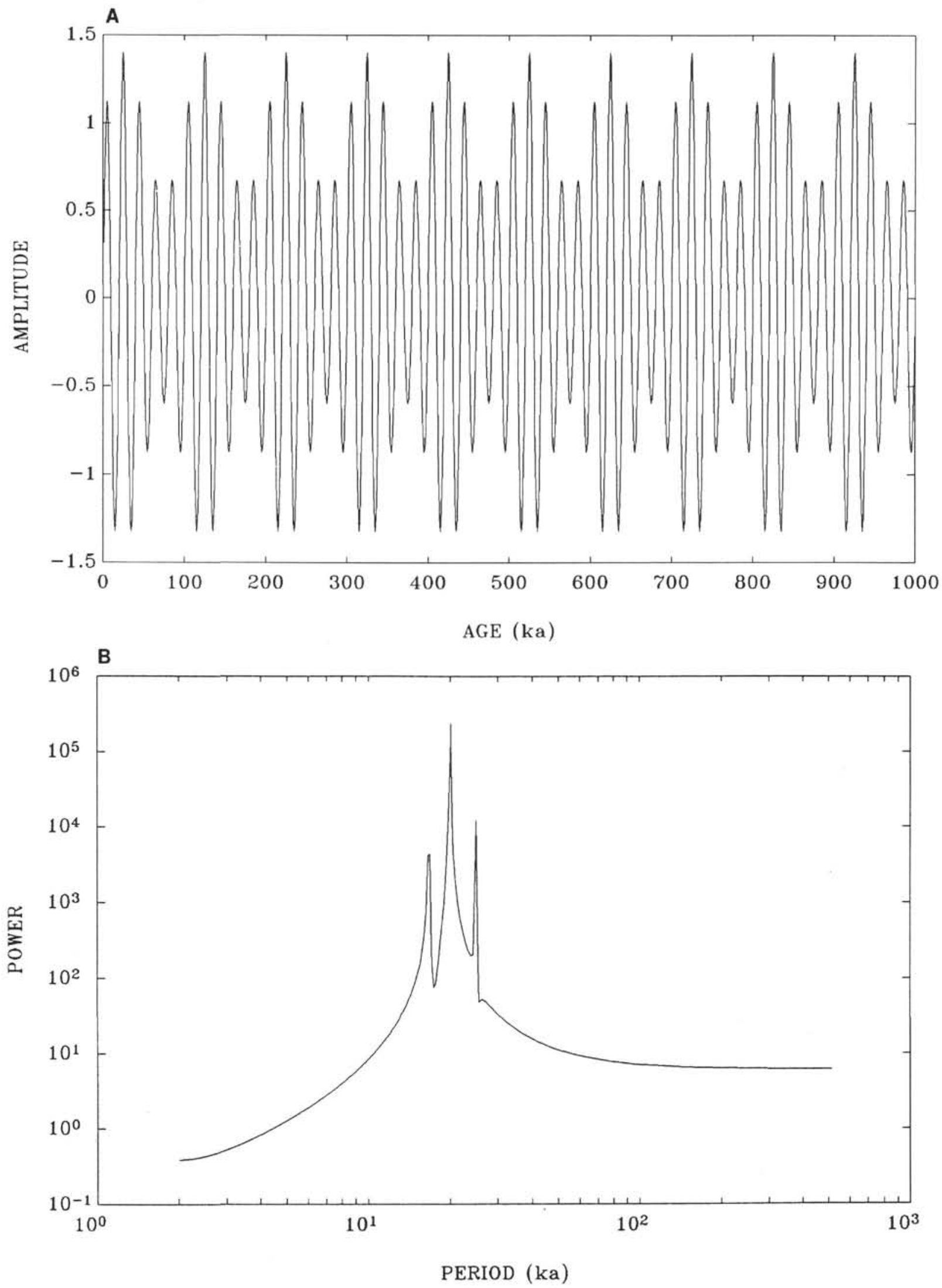

Figure 2. A. Plot of $F(t)=\left(1+\beta \sin \left(2 f_{2} t\right)\right) \sin \left(2 f_{1} t\right)$, with $f_{1}=1 / 20,000$ cycles $/ \mathrm{yr}, f_{2}=1 / 100,000$ cycles/yr, and $\beta=0.4$. B. Power spectrum of $F(t)$. Note that there is no 100,000 -yr power. C. Power spectrum of $F^{2}(t)$. Note the strong 100,000 -yr power and no power at 20,000 yr. (Based on Wigley, 1976.) 


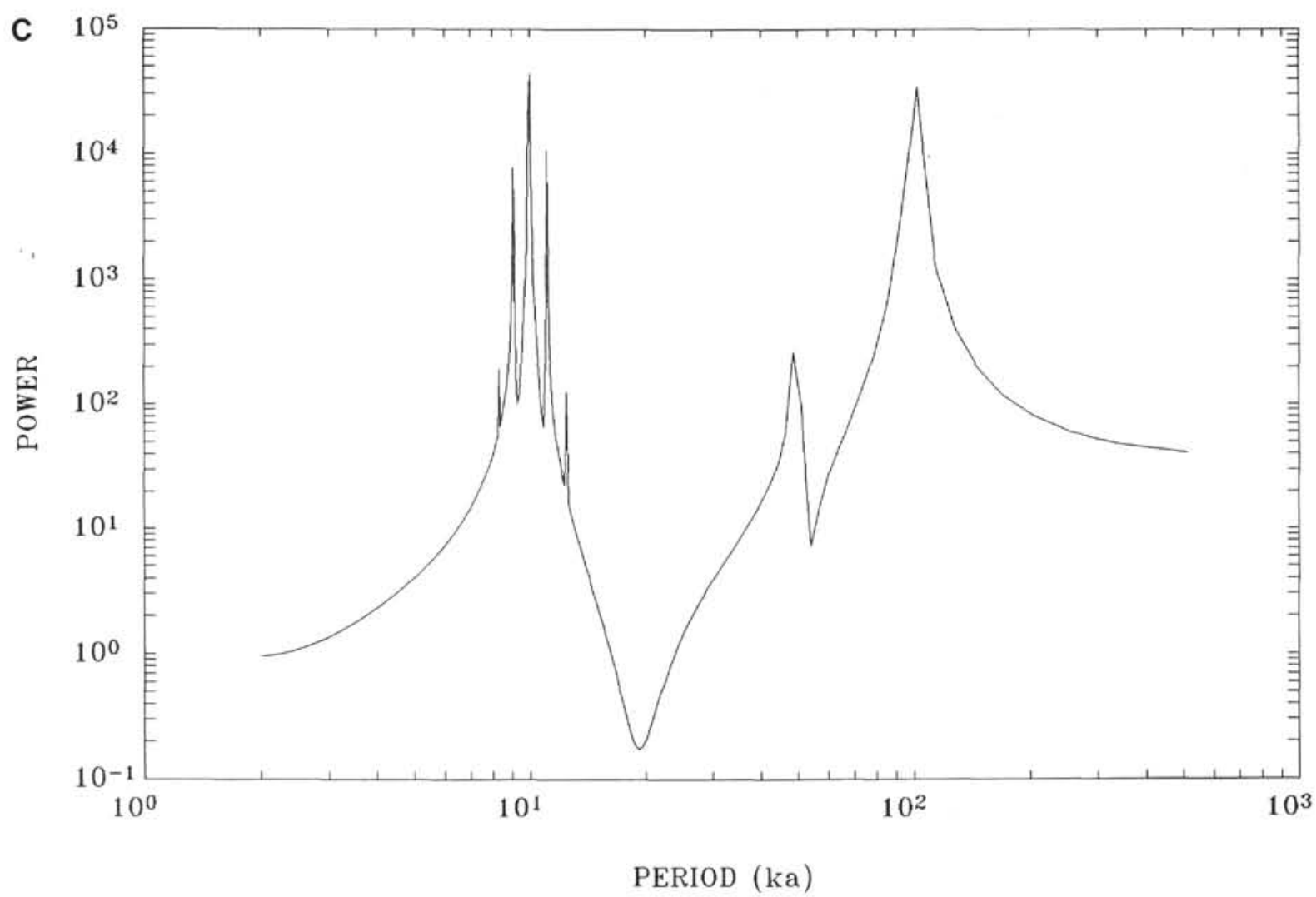

Figure 2 (continued).

of one peak do not overlap with the error bounds on the position of an adjacent peak, using the maximum and minimum sedimentation rates to determine the bounds. Hole 699A has the largest error bounds, where closely spaced peaks may not be separately resolved. For example, the error bounds for the peaks at 129,000 and 147,000 yr for the Hole 699A magnetic susceptibility (Fig. 10) overlap, but the error bounds for the peaks at 147,000 and $234,000 \mathrm{yr}$ do not overlap. For all of the other holes, the error bounds on the spectral peak positions do not overlap.

Note that this effect is not the same as would occur if there was a missing age pick; in that case, one part of the time scale would be stretched and the other part compressed, resulting in the smearing of spectra, the shifting of peaks from their correct positions, and possibly the splitting of spectral peaks. If small time windows are used for analysis, the migration of the spectral peaks as the window is moved can be diagnostic of poor or missing age picks. An example of a set of such evolutive spectra is shown in Figure 7 for GRAPE data from Sites 699,701 , and 704. Windows of a length of $200,000 \mathrm{yr}$ were used, and the center of the window was moved along in steps of 50,000 yr. The peaks appear to be scattered in many instances, and in some cases sets of peaks appear to shift position, as for Holes 699A and 701A for ages of about 0.35 to $0.4 \mathrm{Ma}$ B.P. When a larger window of a length of $500,000 \mathrm{yr}$ is used instead, the peaks are less scattered and the sudden shifts observed in Figure 7 are not present (e.g., Fig. 20). This suggests that the errors in the sedimentation rates are small and are averaged out over a time scale of $500,000 \mathrm{yr}$.

\section{SPECTRAL ANALYSIS TECHNIQUES}

In order to justify our choice of techniques for the spectral analysis of Leg 114 physical-property data, a review of some of the available spectral estimation techniques is in order. In particular, we want to point out some of the assumptions, advantages, and disadvantages of the various techniques. The specific methods considered were the discrete Fourier transform, the Walsh transform, the Lomb-Scargle periodogram, and two maximum-entropy methods. Each spectral estimation technique was tested using a 392 -point $\delta^{18} \mathrm{O}$ data set that had been previously analyzed by Imbrie et al. (1984). Our spectral estimation tests, summarized in Figure 8 , are related to each method as follows.

\section{Discrete Fourier Transform}

The discrete Fourier transform (DFT), $\{\mathrm{Hn}\}$, of an equally spaced data set, $h_{k} \equiv h\left(t_{k}\right), t_{k}=k \delta t, k=0,1,2, \ldots N-1$, where $\delta t$ is the sampling interval, is defined by

$$
H_{n}=\sum_{k=0}^{N-1} h_{k} e^{2 \pi i k n / N} .
$$

Although the DFT can be recast using unequal time intervals, it is normally set up for equally spaced data. Typically, the DFT is defined at integer multiples of the fundamental frequency, $1 / N \delta t$, that is, $H_{n}=H\left(f_{n}\right)$, for

$$
f_{n}=\frac{n}{N \delta t} .
$$

The significance of this set of frequencies is that the DFT, evaluated at these frequencies, contains just enough information to recover the original data. The DFT is estimated in the frequency range $-f_{c} \leq f \leq f_{c}$, and $f_{c}=1 / 2 \delta t$ is the Nyquist frequency, the highest resolvable frequency. Higher frequency components may be present, but show up in the lower 


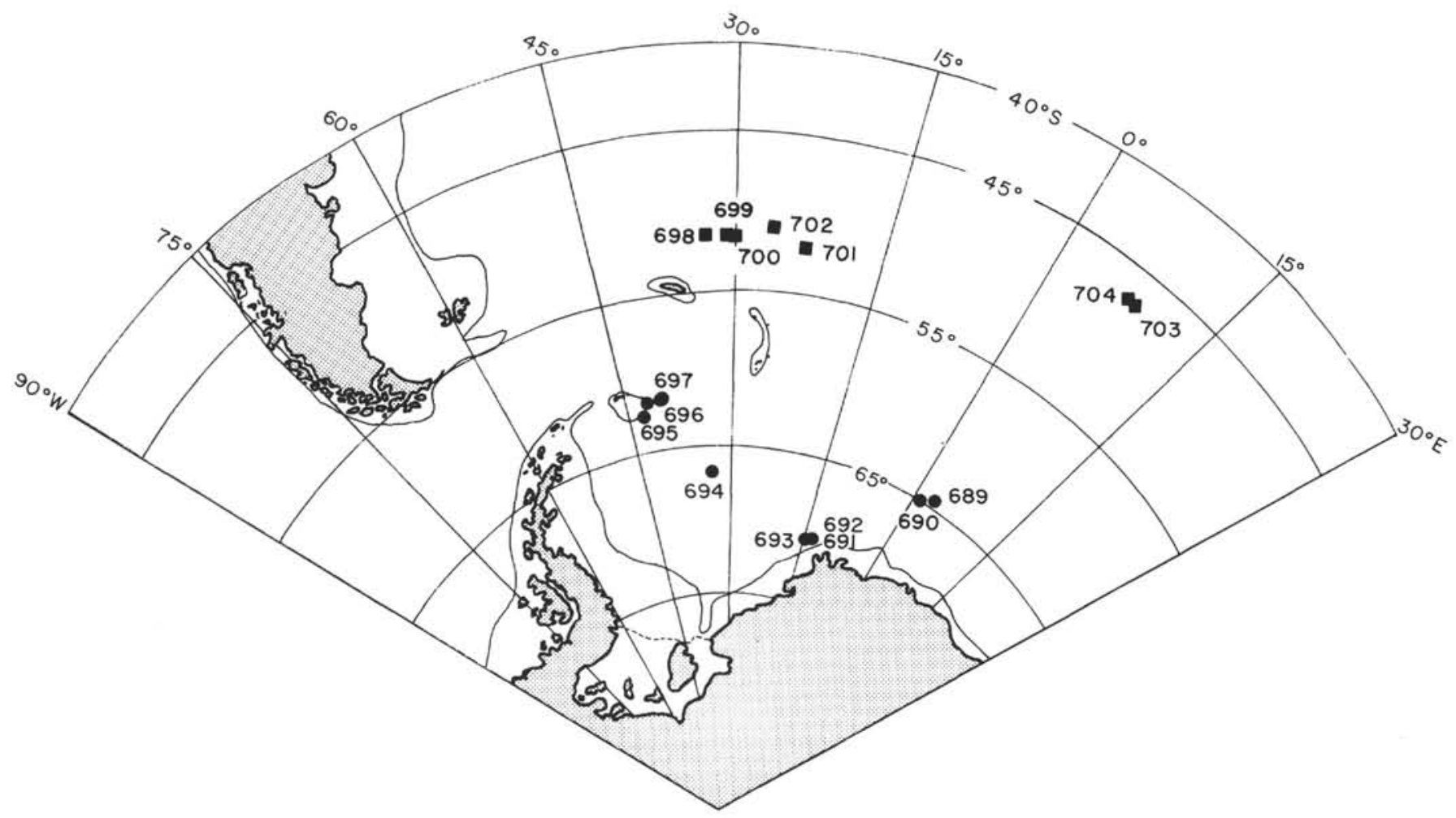

Figure 3. Sites drilled during ODP Legs 113 (circles) and 114 (squares) in the South Atlantic sector of the Southern Ocean. The seven Leg 114 sites form a west-to-east transect across the subantarctic South Atlantic. (From Shipboard Scientific Party, 1988b.)

frequency DFT components, a process called aliasing (e.g., Kanasewich, 1981).

The periodogram, or the estimate of the power in a given frequency interval, is determined from the DFT as

$$
\begin{gathered}
P(0)=\frac{\left|H_{0}\right|^{2}}{N^{2}} \\
P\left(f_{n}\right)=\frac{\left|H_{n}\right|^{2}+\left|H_{-n}\right|^{2}}{N^{2}} \\
P\left(f_{c}\right)=P\left(f_{N / 2}\right)=\frac{\left|H_{N / 2}\right|^{2}}{N^{2} .}
\end{gathered}
$$

As the periodogram of real data is symmetric $(P(f)=$ $P(-f)$ ), all of the information is contained in the positive frequencies. The periodogram can be evaluated at other intermediate frequencies, which results in a plot that looks smoother, but signals at the intermediate frequencies cannot be resolved (Scargle, 1982). The periodogram as defined in the preceding is readily computed, and numerous computer programs are available. However, the DFT periodogram suffers from a property called leakage (Press et al., 1986). The DFT can be thought of as the convolution of an infinite time series with a finite square sampling window (the "boxcar'). The periodogram will be affected by the properties of the window; the boxcar window has sharp edges that introduce substantial high-frequency content into the DFT. We thus seek a sampling window that is both simple to use and minimizes, as much as possible, the effects of leakage. We have opted to use a $20 \%$ split cosine bell (Bloomfield,
1975; Chaghaghi, 1985) with the $\delta^{18} \mathrm{O}$ data. The resulting periodogram (Fig. 8A) contains peaks at 98,000, 41,000 and $19,000 \mathrm{yr}$, in general agreement with the Milankovitch peaks, as well as a split peak at 22,000 and $24,000 \mathrm{yr}$. The frequency resolution, however, is poorly defined.

\section{Walsh Transform}

If instead of the complex exponential functions, as used for the DFT, we use a set of orthonormal square wave functions of amplitude \pm 1 , we may obtain the Walsh transform (Walsh, 1923; Beauchamp, 1975). The periodogram is similar to that for the DFT, except that the Walsh periodogram is less sensitive to sharp transitions in the data, a distinct advantage in dealing with geologic records.

The test data were again windowed using the cosine bell and analyzed using a fast Walsh transform. The resulting periodogram has peaks at 24,000 and $41,000 \mathrm{yr}$, two poorly resolved peaks at $68,000-73,000$ and at $93,000-102,000 \mathrm{yr}$, and no peak at 19,000 yr. The Walsh and DFT results are plotted together for comparison in Figure 8A, and as for the DFT, the frequency resolution is poor.

\section{Lomb-Scargle Periodogram}

Because of the inability of the DFT and the Walsh transforms to detect signals with frequencies not equal to integer multiples of the fundamental frequency, we looked for techniques that would yield better definition in the frequency domain. In addition, traditional applications of the DFT have normally assumed equally spaced data. Interpolation is an obvious solution to obtain equally spaced from unequally spaced data. For a large amount of missing data, however, the DFT will give as much weight to the interpolated data as to any equal length of real data. Interpolation can also only be reliably used to get a lesser number of equally spaced data; we cannot reliably obtain more data points than the number of real data that we have. 

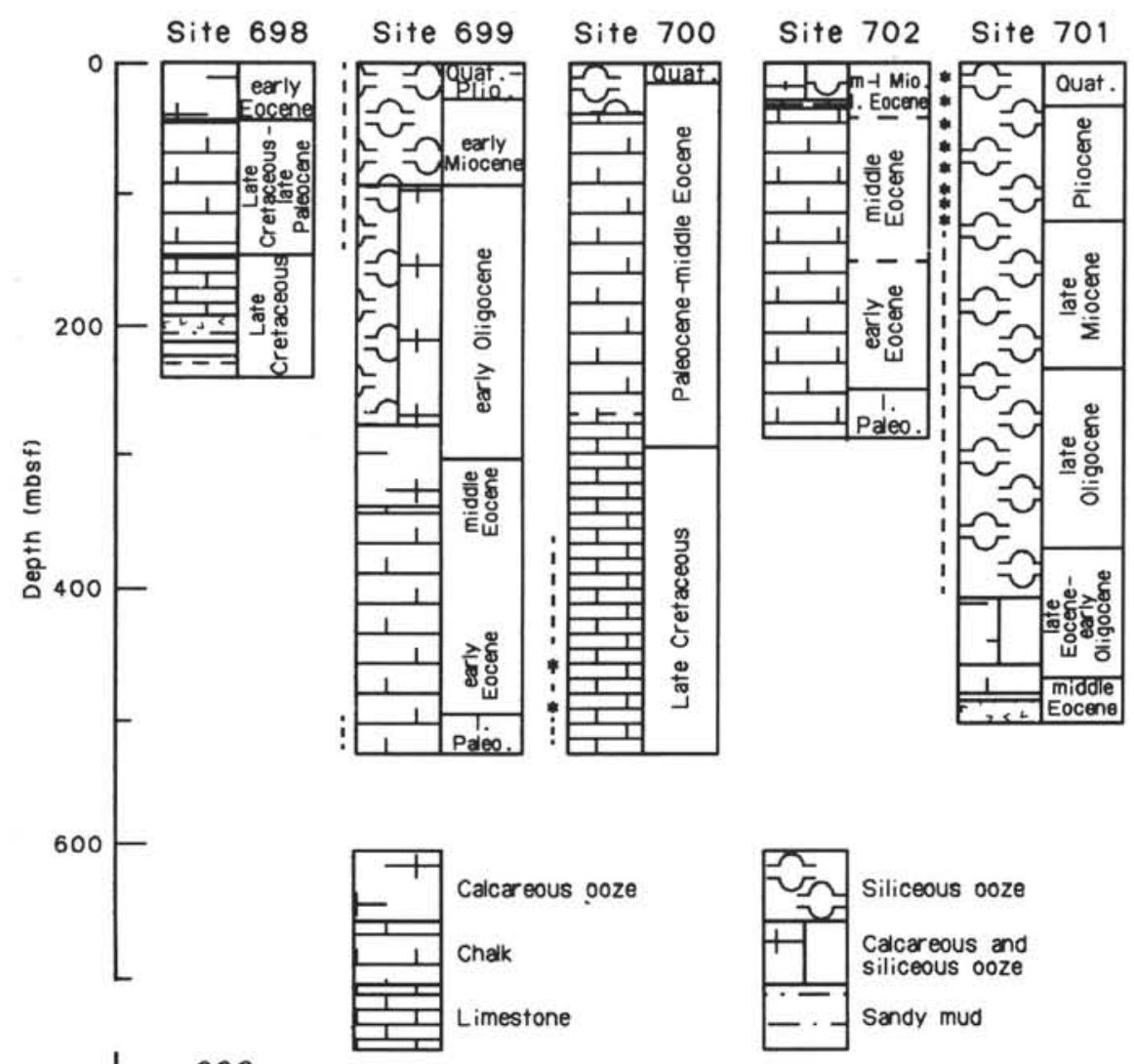

Site 704

Site 703
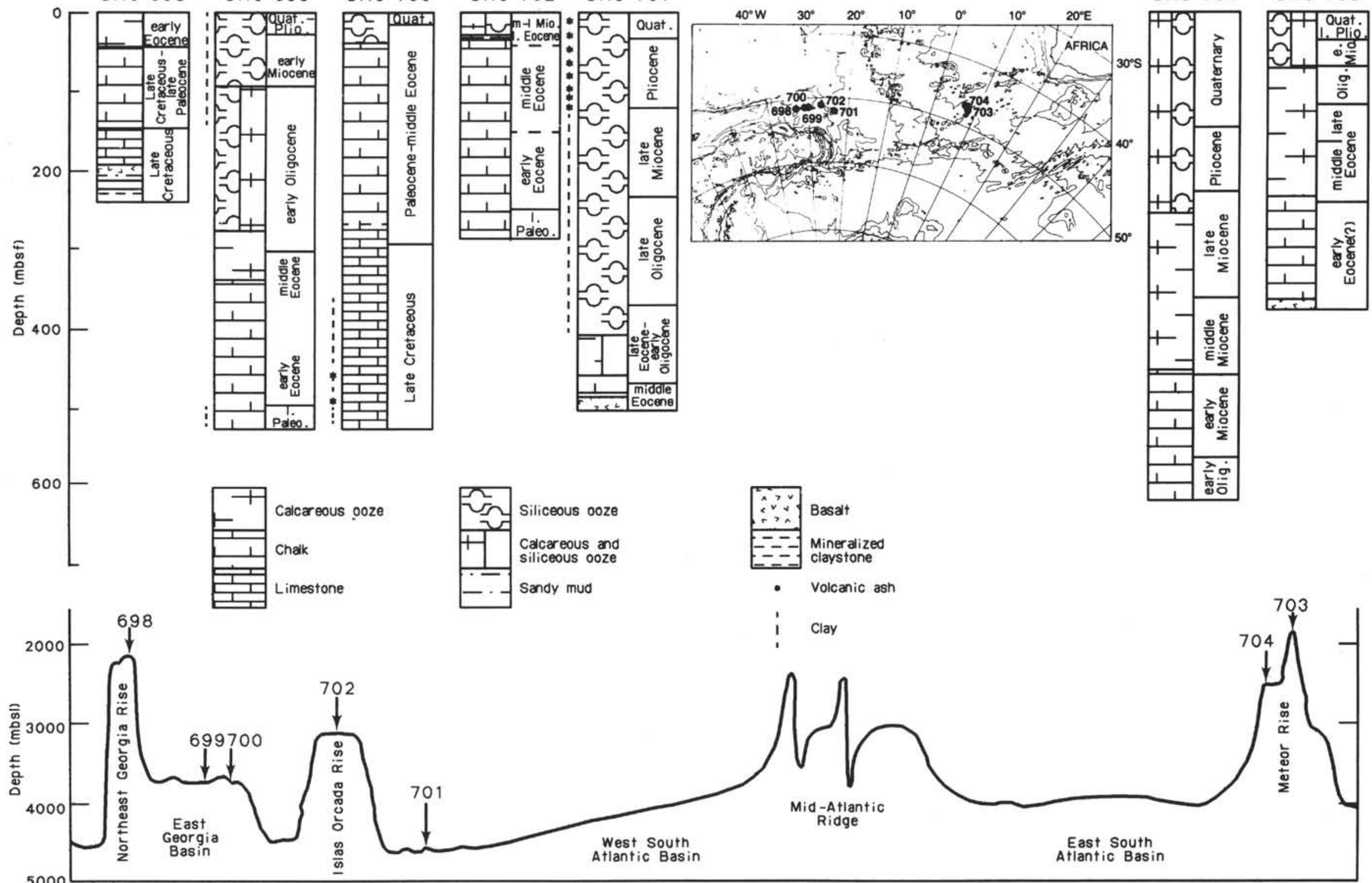
D. C. NOBES ET AL.

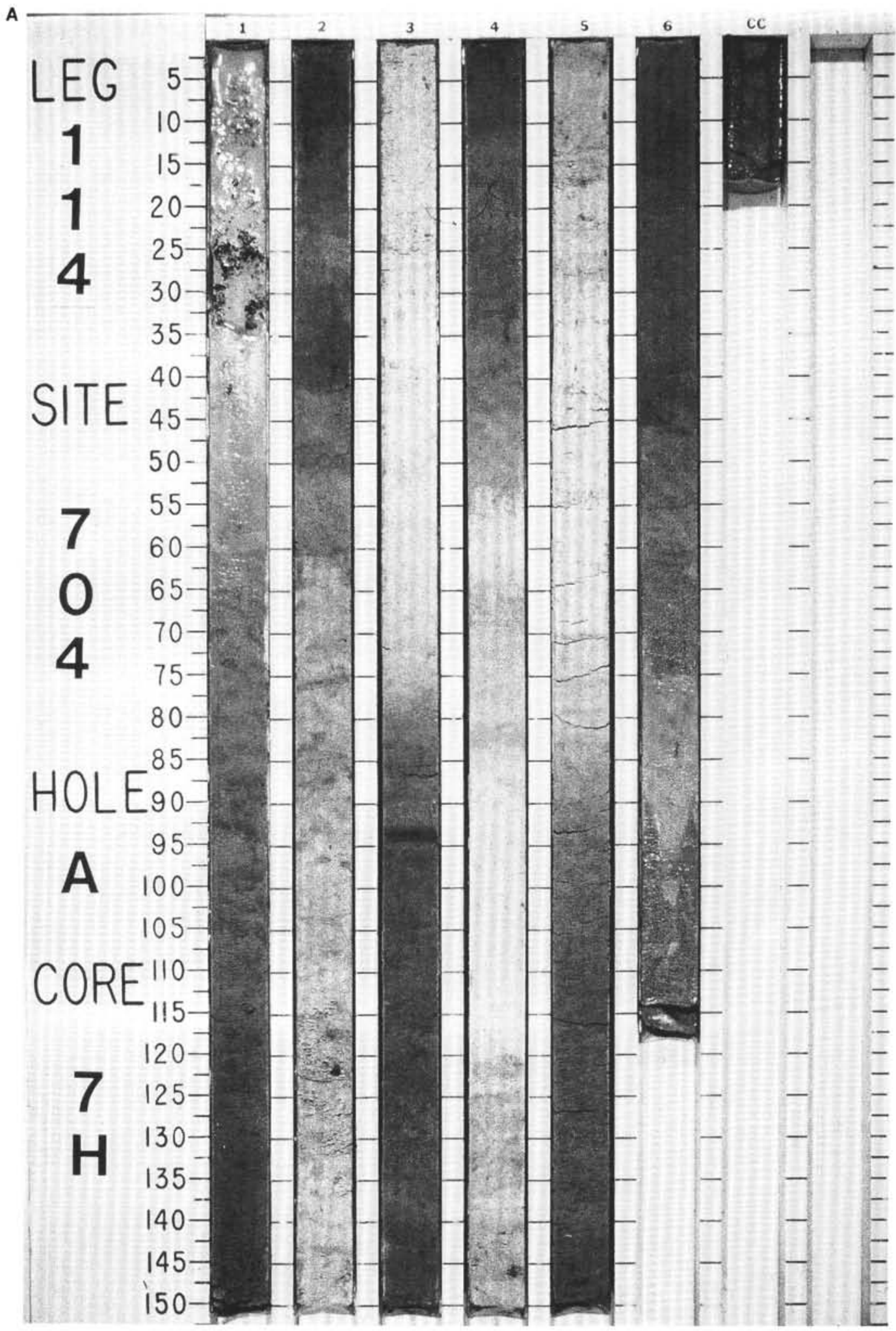

Figure 5. A. Distinct alternating intervals of dark (red or green) and light (white) sediments are composed of siliceous (diatom) and calcareous (nannofossil) oozes, respectively, in Core 114-704A-7H. B. Alternating sediment layers can be clearly identified in a plot of the GRAPE density for Core 114-704A-7H. The (white) nannofossil oozes (labeled calcareous) are higher in density, and the (red) diatom oozes (siliceous) are lower in density, 


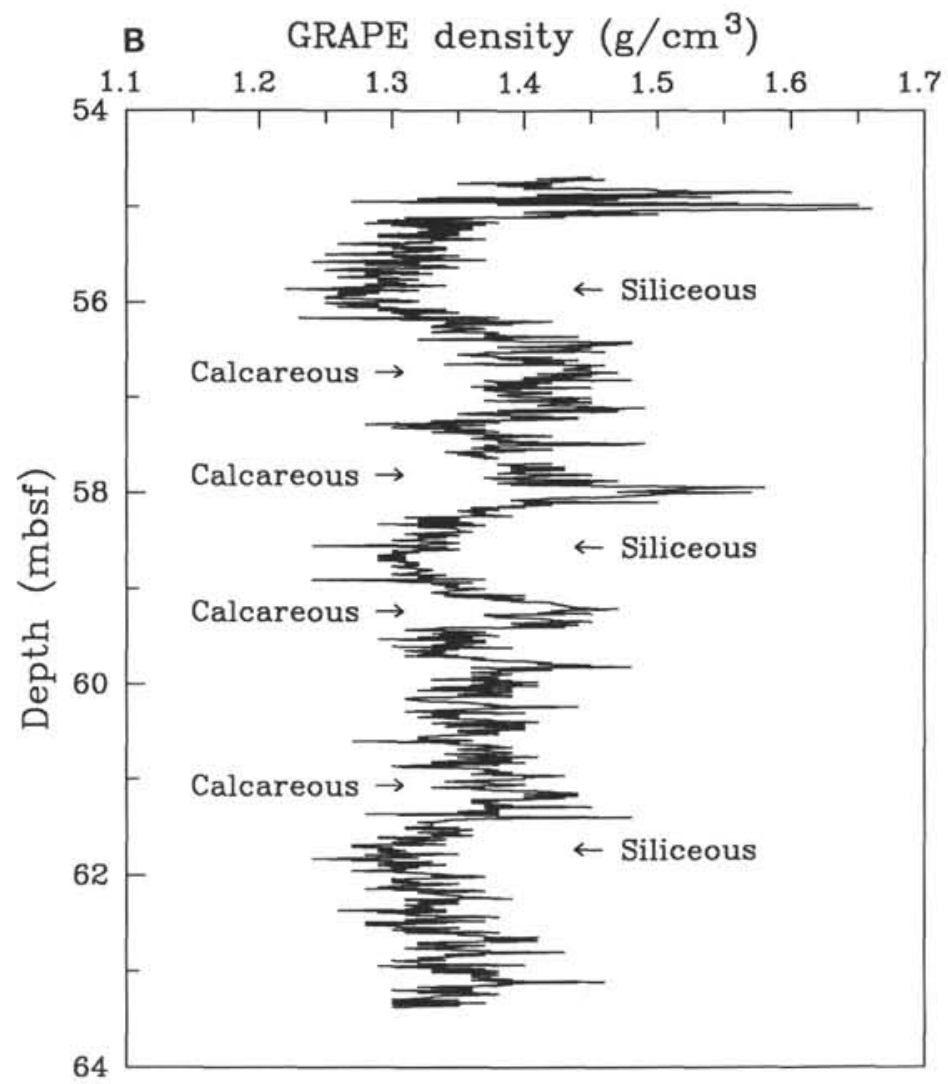

Figure 5 (continued).

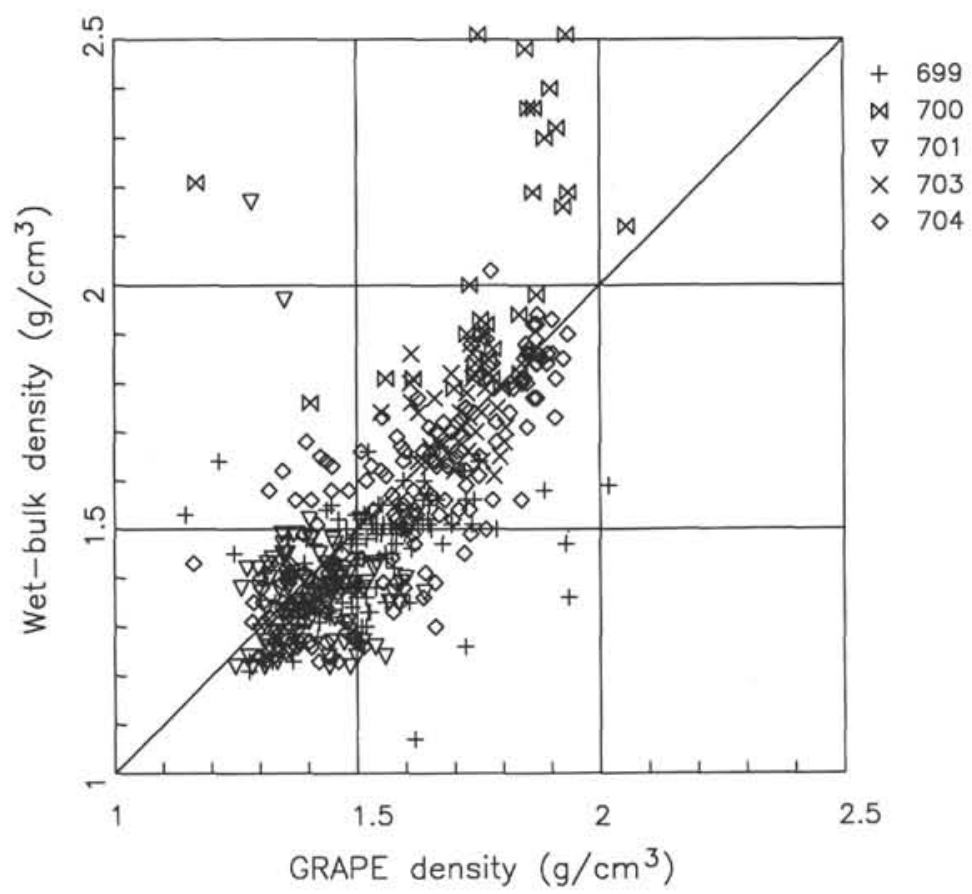

Figure 6. Laboratory wet-bulk density vs. GRAPE density. The data points cluster about the diagonal solid line of slope 1, representing equality. Only sediments from Sites 699, 701, and 704 are Quaternary in age. 
A technique that was particularly geared to unequally spaced data would be advantageous in dealing with segments with distinctly different sedimentation rates, data gaps due to missing core, et cetera. The Lomb-Scargle technique (Lomb, 1976; Scargle, 1982; Press and Teukolsky, 1988) is designed for unequally spaced data and includes a simple test for the statistical significance of a spectral peak. Given a set of data $\left\{f_{i}\right\}$ sampled at $N$ times $\left\{t_{i}\right\}$, then the normalized Lomb-Scargle periodogram is defined as

$$
\begin{aligned}
P_{L S}(\Omega) & =\frac{1}{2 \sigma^{2}}=\left[\frac{\left\{\Sigma_{i}\left(f_{i}-\bar{f}\right)^{\left.\cos \Omega\left(t_{i}-T\right)\right\}^{2}}\right.}{\Sigma_{i} \cos ^{2} \Omega\left(t_{i}-T\right)}\right. \\
& \left.+\frac{\left\{\Sigma_{i}\left(f_{i}-\bar{f}\right) \sin \Omega\left(t_{i}-T\right)\right\}^{2}}{\Sigma_{i} \sin ^{2} \Omega\left(t_{i}-T\right)}\right]
\end{aligned}
$$

where $f$ and $\sigma^{2}$ are the mean and variance of the data set:

$$
\bar{f}=\frac{1}{N} \sum_{i=0}^{N-1} f_{i}
$$

and

$$
\sigma^{2}=\frac{1}{N-1} \sum_{i=0}^{N-1}\left(f_{i}-\bar{f}\right)^{2}
$$

and $T$ is defined by

$$
\tan (2 \Omega T)=\Sigma_{j} \sin \left(2 \Omega^{t_{j}}\right) / \Sigma_{j} \cos \left(2 \Omega t_{j}\right)
$$

Signals can be resolved at frequencies that are not integer multiples of the apparent fundamental frequency, twice the inverse of the sampling interval, or the apparent Nyquist frequency, the inverse of twice the average sampling rate. This higher frequency resolution is called superresolution (e.g., Minami et al., 1985). Lomb (1976) showed that the offset $T$ makes the Lomb-Scargle periodogram equivalent to the equation obtained by fitting the data with the linear leastsquares model:

$$
h(t)=A \cos \Omega(t-T)+B \sin \Omega(t-T) .
$$

$T$, as defined in the preceding, makes the periodogram invariant to a shift in the time origin.

In the case of equally spaced data, the unsmoothed DFT periodogram is equivalent to the Lomb-Scargle periodogram at frequencies equal to integer multiples of the fundamental frequency. However, this is not necessarily true for any other frequency and is not necessarily true for any frequency when the data are unequally spaced (Scargle, 1982).

Horne and Baliunas (1986) found that the number of independent frequencies, $M$, is nearly equal to $N$ when the data points are approximately equally spaced and when equally spaced frequencies cover the range from 0 to the Nyquist frequency, where the Nyquist is defined as for equally spaced data. The number of independent frequencies will be reduced if the data are "clumped" into a few distinct groups; in that case $M$ is reduced by the number of groups.

If we assume that the data set is the sum of a periodic signal and independent white noise, then we can determine the statistical significance of a given Lomb-Scargle spectral peak. We test the null hypothesis that the data values are independent Gaussian random values. Scargle (1982) showed that $\mathrm{P}_{L S}(\Omega)$ has an exponential distribution with unit mean, that is, the probability that $\mathrm{P}_{L S}(\Omega)$ will lie between some value $z$ and $z+d z$ is $e^{-z} d z$. If $P_{L S}(\Omega)$ is determined for the $M$ independent frequencies, then the probability that the power is never larger than $z$ is $\left(1-e^{-z}\right)^{M}$. Therefore,

$$
p(>z) \equiv 1-\left(1-e^{-z}\right)^{M}
$$

is the "false alarm" probability for the null hypothesis. A small value of $p(>z)$ at a given $\Omega$ means that the spectral peak is highly significant. A value of 0.5 , or less, for the false alarm probability means that the spectral peak is no more significant than random. Given the number of independent frequencies for which we calculate the Lomb-Scargle periodogram, we may test the spectral peaks for their significance. The more frequencies for which we determine $P_{L S}(\Omega)$, the less some "small" peak is significant.

The $\delta^{18} \mathrm{O}$ data were tapered with a $20 \%$ split-cosine bell and then analyzed using the Lomb-Scargle technique. The frequencies were oversampled by a factor of 16 , and the periodogram was determined for the range of periods from 10,000 to $10^{6} \mathrm{yr}$. The results, as shown in Figure 8B, yield no significant peaks at $19,000 \mathrm{yr}$, a split peak at $23,000 \mathrm{yr}$, and peaks at 41,000 and 100,000 yr that are at least $95 \%$ significant. There are also spectral peaks that are at least $95 \%$ significant at $60,000,67,000,120,000$, and $147,000 \mathrm{yr}$. The general form of the Lomb-Scargle periodogram is the same as for the DFT and Walsh spectra.

In summary, the Lomb-Scargle method does not require equally spaced data, has a simple statistical test for spectral peak significance, is easy to implement, and produces a superresolved spectrum that for the $\delta^{18} \mathrm{O}$ data generally agrees with the DFT and Walsh spectral estimates.

\section{Maximum Entropy Spectral Estimation}

Maximum entropy techniques choose the power spectral density that corresponds to the most random time series that still agrees with the sampled data. Alternatively, the estimated spectrum is the smoothest that is still consistent with the known data. Because of the inherent structure of maximum entropy methods, windowing of the data is not required. The underlying model of the maximum entropy power spectral estimation is that of a $p^{\text {th }}$ order stochastic autoregressive model:

$$
x_{i}=\sum_{k=1}^{P} a_{k} x_{i-k}+e_{i}, i=P, \ldots N-1
$$

where the set $\left\{a_{k}\right\}$ is the set of autoregressive model coefficients, and $e_{i}$ is the autoregressive model Gaussian white noise input sequence. The stochastic nature of the model further imposes the condition that the data are stationary in mean and variance, that is, the mean and variance depend only on the time lag, $k$.

The maximum entropy $(M E)$ power spectral density is given by

$$
P_{M E}(f)=\sigma_{e}^{2} \mid 1+\sum_{k=1}^{P} a_{k} e^{i 2 p i f k \mid 2},
$$



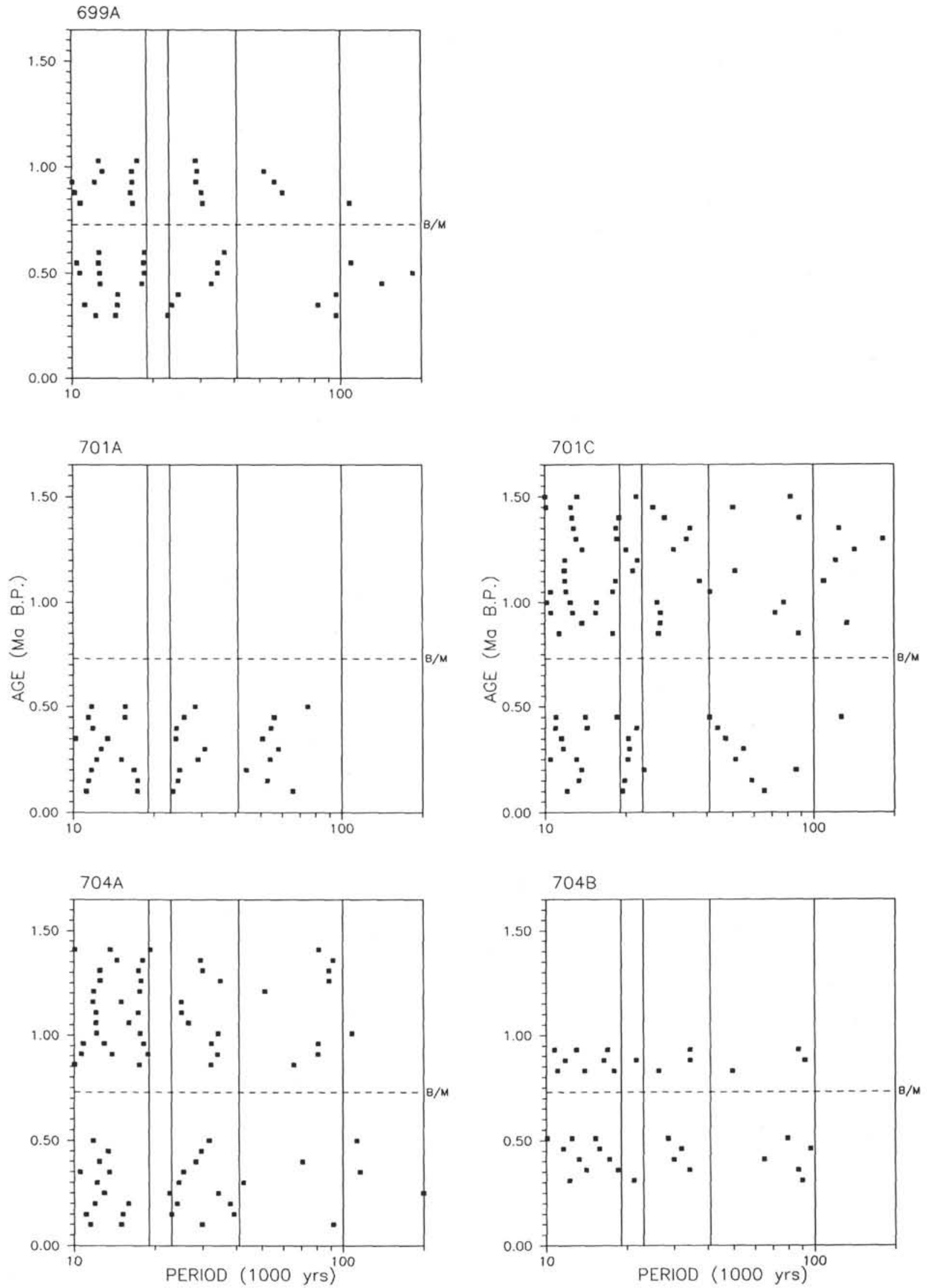

Figure 7. Singular value decomposition maximum entropy 200,000 -yr window evolutive periodograms for the GRAPE density in Holes 699A, 701A, 701C, 704A, and 704B. The "jump" in the positions of the peaks in Holes 699A and 701A at 0.40 and $0.35 \mathrm{Ma}$ B.P., respectively, is probably indicative of problems in the depth-to-age conversion. 
A) DFT/Walsh

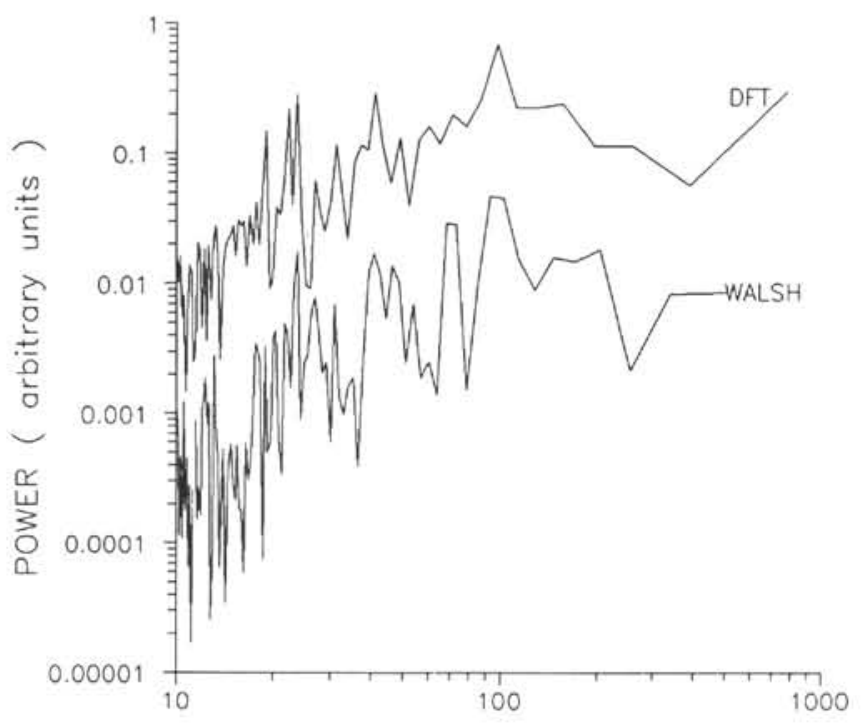

C) Burg $M E$

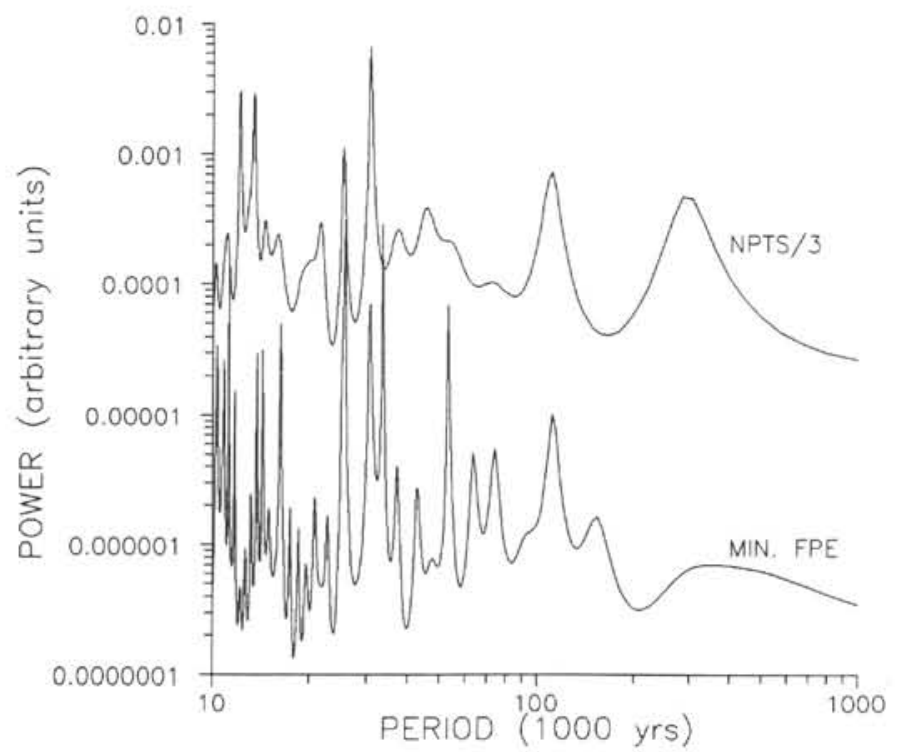

B) Lomb-Scargle

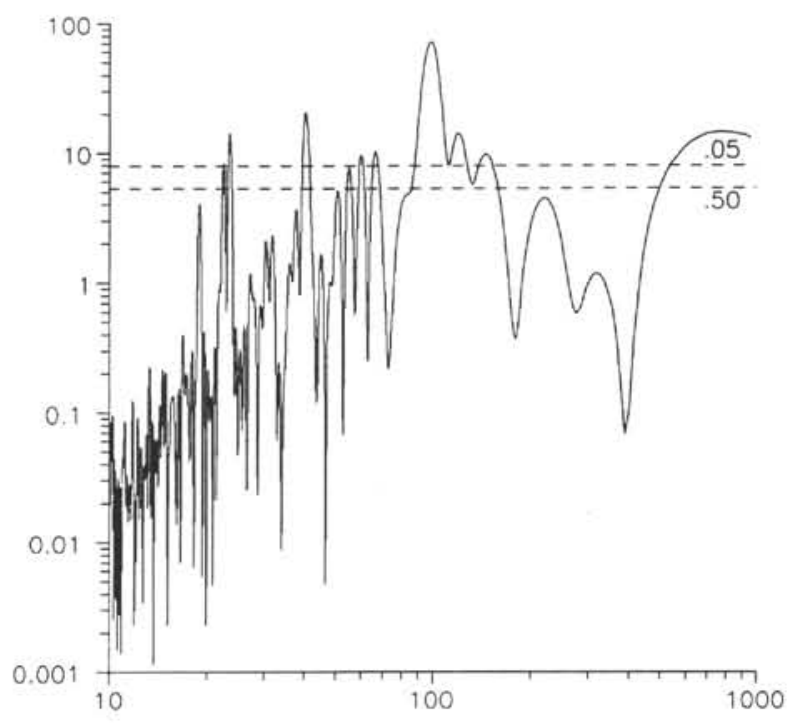

D) SVD ME

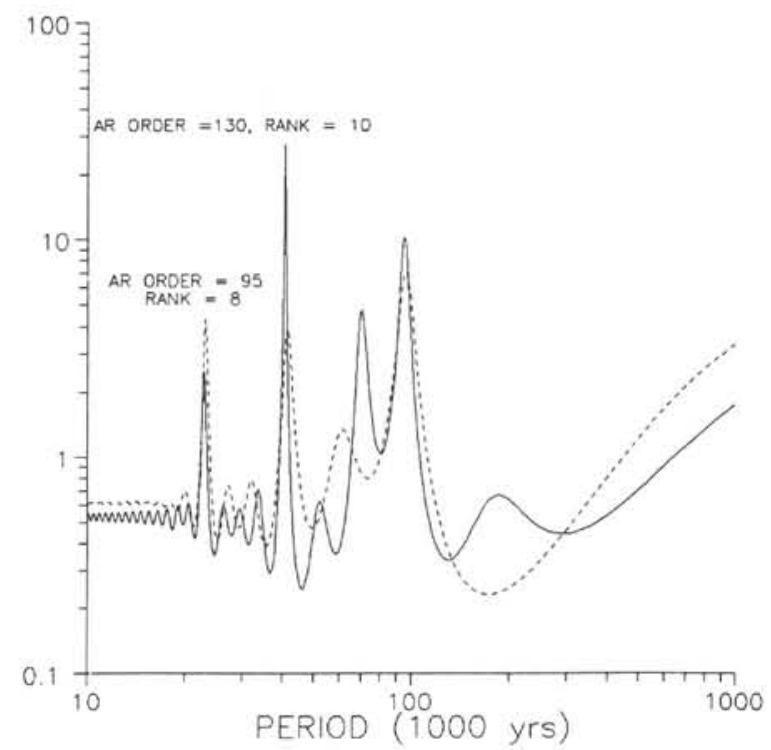

Figure 8. Spectral analysis of the $\delta^{18} \mathrm{O}$ test data set of Imbrie et al. (1984). A. The DFT and Walsh transforms have many spectral peaks, including those expected for Milankovitch cycles, but the background is high and the frequency resolution is poor. B. The Lomb-Scargle periodogram is similar in appearance to the DFT and Walsh spectra, but has better frequency resolution and the significance of the peaks is easily established by comparison with the lines of $95 \%(0.05)$ and $50 \%(0.50)$ confidence that the peak is not random. C. The Burg maximum entropy spectra have better frequency resolution and better noise suppression, but the spectral peaks are not consistent with changes in the order, that is, changes in the number of spectral parameters, and spurious peaks are present. D. The singular value decomposition maximum entropy method yields the smoothest spectrum, yet the peaks are consistent for a wide range of autoregressive orders. The presence of a peak is an indication of significance, but the amplitude of a given peak carries no explicit information.

where $\sigma_{\mathrm{e}}^{2}$ is the variance of $\left\{e_{i}\right\}$. The power spectral density estimate is dependent on the estimates of the autoregressive coefficients and the order $P$. We seek a power spectral density estimate that is consistent over a wide range of orders, $P$, because methods to predict the order, such as Akaike's information criteria and the final prediction error (Kanasewich, 1981), tend to underestimate the order required to obtain an adequate spectrum. Therefore, a method is sought to estimate the autoregressive parameters that will produce a spectrum independent of the autoregressive order for a wide range of orders and that does not produce spurious peaks. Two methods were tested: the Burg (1975) method and the singular value decomposition method of Minami et al. (1985).

Burg's method iteratively determines the autoregressive coefficients using the prediction error power and the autocovariance function of the data, which are separately estimated. The method can suffer from ill-conditioning for large autoregressive orders and is sensitive to noise in the data. The Burg 
maximum entropy estimates are shown in Figure $8 \mathrm{C}$ for a range of autoregressive orders. Spectral peaks at 23,000 and $41,000 \mathrm{yr}$ were not obtained whereas a number of spurious peaks appeared for autoregressive orders ranging from onethird of the number of data points to the estimate of the final prediction error using $60 \%$ of the number of data points. In addition, the spectral peak that appears at $100,000 \mathrm{yr}$ in the other spectra is shifted in the Burg maximum entropy spectrum to a longer period.

The other method for estimating autoregressive parameters, the singular value decomposition method, uses a matrix decomposition method. The autoregressive model can be written in matrix form as $\boldsymbol{X a}+e=x$, where

$$
\begin{aligned}
& \mathrm{X}=\left[\begin{array}{ccc}
\mathrm{x}_{0} & \ldots & \mathrm{x}_{\mathrm{p}-1} \\
\mathrm{x}_{1} & \ldots & \mathrm{x}_{\mathrm{p}} \\
\cdot & \cdot \\
\cdot & \cdot \\
\cdot & \cdot \\
\mathrm{x}_{\mathrm{N}-\mathrm{P}-1} & \mathrm{x}_{\mathrm{N}-2}
\end{array}\right] a=\left[\begin{array}{c}
\mathrm{a}_{\mathrm{p}} \\
\cdot \\
\cdot \\
\cdot \\
\cdot \\
\mathrm{a}_{1}
\end{array}\right] e=\left[\begin{array}{c}
\mathrm{e}_{\mathrm{p}} \\
\cdot \\
\cdot \\
\cdot \\
\cdot \\
\mathrm{e}_{\mathrm{N}-1}
\end{array}\right] \\
& x=\left[\begin{array}{c}
\mathrm{x}_{\mathrm{p}} \\
\cdot \\
\cdot \\
\cdot \\
\cdot \\
\mathrm{x}_{\mathrm{N}-1}
\end{array}\right]
\end{aligned}
$$

In the absence of noise, $X a \approx x$. Using the singular decomposition method, $\boldsymbol{X}$ can be decomposed into

$$
\boldsymbol{X}=\boldsymbol{U} \boldsymbol{\Gamma} \boldsymbol{V}^{T}=\sum_{i=1}^{P} \gamma_{i} u_{i} v_{i}^{T},
$$

where $\Gamma$ is a diagonal matrix of ordered eigenvalues, $\gamma_{\mathrm{i}}$ and $\boldsymbol{U}$ and $\boldsymbol{V}$ are unitary matrices of eigenvectors. Then the MoorePenrose generalized inverse of $\boldsymbol{X}, \boldsymbol{X}^{+}$, is (Menke, 1985)

$$
X^{+}=\sum_{i=0}^{L} v_{i} u_{i}^{T} / \gamma_{i},
$$

where $L$ is the number of significant eigenvalues, which can be determined either from a plot of $\gamma_{i}^{2}$ with respect to index $i$, set a priori, or set such that the proportion of rejected energy, $\epsilon$, is some predetermined value (Friere and Ulrych, 1988), where $\epsilon$ is defined as

$$
\epsilon=\frac{\sum_{i=L+1}^{P} \gamma_{i}^{2}}{\sum_{i=1}^{P} \gamma_{i}^{2}} .
$$

The vector of the estimated autoregressive parameters is then given as the product of the Moore-Penrose inverse and $\boldsymbol{X}$.

By choosing $L<P$, we may decrease the noise through the elimination of insignificant energy. Unfortunately, we now have two free parameters, the autoregressive order, $P$, and the number of significant eigenvalues, $L$. Minami et al. (1985) showed for Fourier transform spectroscopic data that $L$ was the principal variable that determined the number of spectral peaks for a wide range of autoregressive orders. The singular value decomposition technique has the disadvantage of being expensive to compute, and it can only be used for small data sets. For this study, $N$ was restricted to be less than 600 data points.

The 392-point $\delta^{18} \mathrm{O}$ data set was analyzed using the singular value decomposition autoregressive method for $P=$ 130 (one-third of $N$ ) and $L=10$ and for $P=95$ (one-quarter of $N$ ) and $L=8$. The autoregressive orders, that is, the values of $P$, are typical of autoregressive models for maximum entropy spectra. Note, however, that the number of significant parameters, $L$, is a fraction of the autoregressive order. In Figure 8D, the value of $L$ was chosen such that $\epsilon=$ 0.5 . In practice, this method of choosing $L$ yields stable results and is simpler than choosing $L$ from an eigenvalue plot. Strong spectral peaks were obtained at 100,000, 41,000, and 23,000 yr for both autoregressive orders. An additional strong peak at $60,000 \mathrm{yr}$ was found for $P=130$ and $L=10$, consistent with the Walsh and the Lomb-Scargle periodograms. We must point out that the amplitudes of the peaks are not necessarily representative of the amount of energy present at that period. Instead, the peaks that are present are merely those that are minimally required by the data given the maximum entropy assumption.

\section{Statistical Similarity of Spectra}

The analysis presented in this study requires the comparison of spectra for different physical properties from different holes, with the identification of spectral peaks common to many properties and holes. Two measures were taken in an attempt to eliminate any arbitrary selection of peaks. First, the peaks labeled in the periodograms that follow are the peaks that form continuous trends in the $500,000-\mathrm{yr}$ evolutive periodograms. This is done to eliminate those peaks in the periodograms that may be an artifact of problems in depth-toage conversion.

Second, we want to identify only those peaks that appear in multiple data sets, avoiding peaks that may be artifacts of the specific measurement process. The coherency between two data sets was not calculated because it required the use of a smoothed DFT, with all of the attendant weaknesses. Instead, a Kolmogorov-Smirnov statistical test (Conover, 1980; Press et al., 1986) was performed on Lomb-Scargle periodograms to determine the similarity between two power spectral distributions over a given range of periods. The Kolmogorov-Smirnov statistic is similar to the coherency, but can be applied to any two data distributions. The power spectra were sampled at equally spaced frequencies at a rate of two times greater than the average fundamental frequency, and a rolling window of 21 power samples was used to determine the KolmogorovSmirnov significance between two power spectral distributions over various ranges of periods. The KolmogorovSmirnov significance was then plotted at the midpoint period of the 21-sample rolling window. The Kolmogorov-Smirnov rolling statistic allows us to determine the similarity directly from the Lomb-Scargle periodograms.

The utility and some of the failings of such an approach are demonstrated in Figure 9. The carbonate content and GRAPE density Lomb-Scargle periodograms from Hole 704B for the Brunhes have common peaks at periods of $52,000,64,000$, $78,000,97,000,130,000$, and 198,000 yr. Because the Kolmogorov-Smirnov test measures the similarity of two distributions, not only is the spectral peak position important, but the relative distribution of power within the sampling window is also important. This explains why there is a high Kolmogorov- 

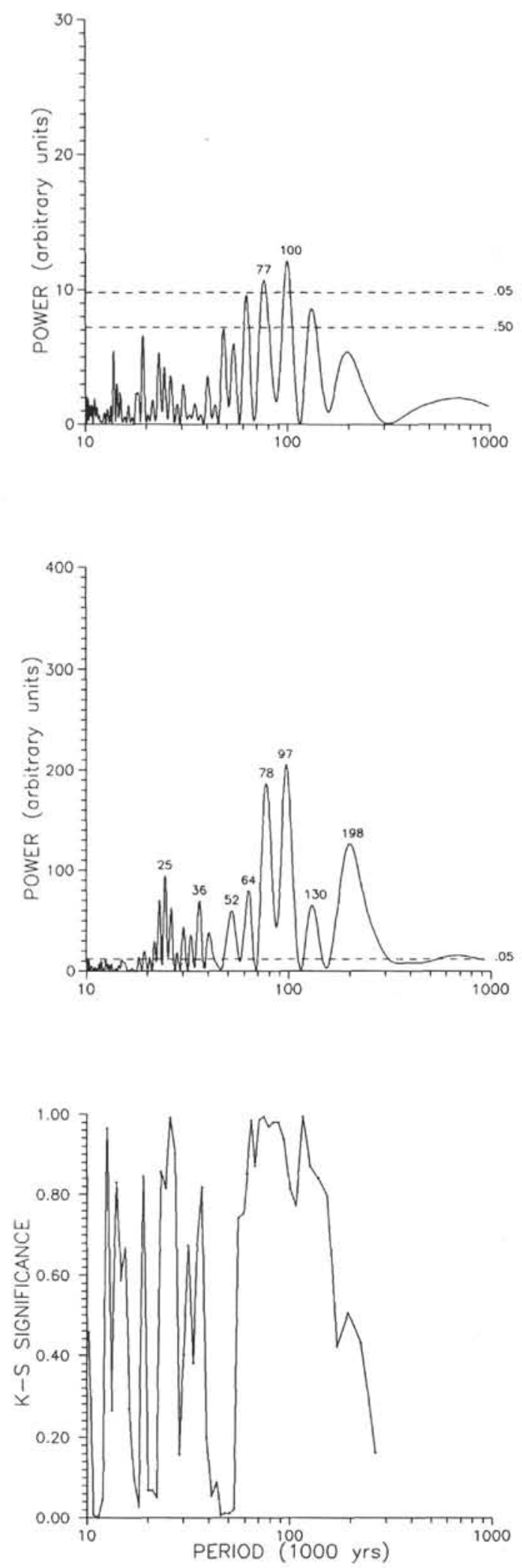

Figure 9. Lomb-Scargle periodograms for the Brunhes from Hole 704B for carbonate content (top) and GRAPE density (middle), with the Kolmogorov-Smirnov test of similarity (bottom) of the two power distributions. The peaks at $64,000,78,000,97,000$, and $130,000 \mathrm{yr}$ in both periodograms correspond to a high Kolmogorov-Smirnov significance.
Smirnov significance for the peaks between 64,000 and $130,000 \mathrm{yr}$, but not at 52,000 and $198,000 \mathrm{yr}$.

\section{Summary}

Two methods were ultimately selected for further analysis of the physical-property data: the Lomb-Scargle technique and the singular value decomposition maximum entropy method. The Lomb-Scargle technique can be used with unequally spaced data and has a simple test of spectral peak significance. The Lomb-Scargle spectra were then used for Kolmogorov-Smirnov statistical similarity tests. The singular value decomposition maximum entropy method produces a smooth spectrum with reduced noise, but although only the significant spectral parameters contribute to the periodogram, the peak amplitudes cannot be used for analysis. The singular value decomposition spectral estimate is better able to resolve the shorter period peaks, whereas the Lomb-Scargle technique appears to resolve the longer period peaks better. We found the differences to be most apparent when we compared the separate Brunhes, Matuyama, and evolutive spectral analyses. The magnetic susceptibility can be used to illustrate this. Because of its generally equally spaced but coarser sampling, the magnetic susceptibility may be analyzed using both the Lomb-Scargle and singular value decomposition maximum entropy techniques for the Brunhes and Matuyama periods. The results are shown for the Brunhes from Holes 699A and 701A (Fig. 10) and for the Matuyama from Holes 699A and 704A (Fig. 11).

\section{RESULTS AND DISCUSSION}

Spectra of the physical-property data were produced for the whole of the Quaternary using the Lomb-Scargle technique. Kolmogorov-Smirnov statistical similarity distributions were calculated from the Lomb-Scargle spectra. The Quaternary data were further subdivided at the Brunhes/Matuyama boundary (0.73 Ma B.P.). Lomb-Scargle spectral estimation was performed on these data subsets separately.

The singular value decomposition maximum entropy method was restricted in use to data segments where the data were equally spaced, that is, with no large data gaps and an approximately constant sedimentation rate. Because of the limit on the size of the data set for the singular value decomposition maximum entropy method periodogram, the data were resampled such that the number of data points fell below 600 points while maintaining equally spaced samples. The autoregressive order cutoff was set to one-quarter of the number of data points and the rank was set so that the amount of rejected energy was one-half of the total energy, consistent with the results of the oxygen isotope analysis described previously (Fig. 8D).

Lomb-Scargle evolutive spectra were produced for all three physical properties considered in this study, using 200,000 -and $500,000-\mathrm{yr}$ windows and rolling the midpoint of the window along at intervals of 50,000 yr. Singular value decomposition maximum entropy evolutive spectra were produced for the GRAPE and the magnetic susceptiblity data using 200,000 -and 500,000 -yr windows. The evolutive spectra were produced to determine the time evolution, if any, of the response to cyclic forcing and, as described previously, to pinpoint problems in the depth-to-age conversion. The 200,000 -yr windows did show some variability in the positions of spectral peaks, including some shifts in sets of peaks, which we have interpreted as resulting from missing or erroneous age picks. The $500,000-y r$ windows do not show the same degree of variability, nor do we see sudden shifts in the positions of sets of spectral peaks, and we have concluded 


\section{Brunhes}
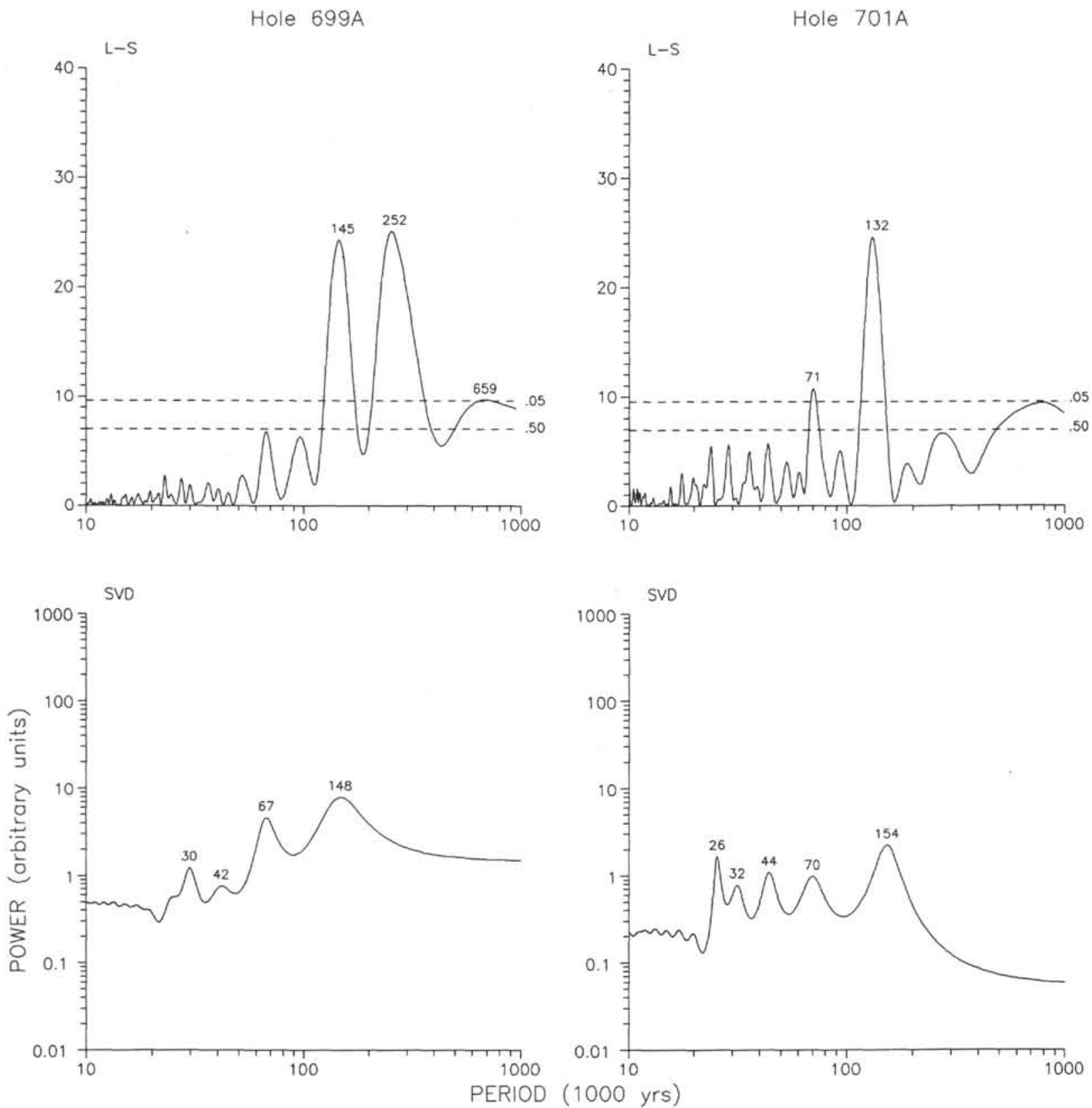

Figure 10. Lomb-Scargle and singular value decomposition maximum entropy magnetic susceptibility periodograms for Holes $699 \mathrm{~A}$ and $701 \mathrm{~A}$ for the Brunhes. The singular value decomposition method yields the short period peaks whereas the Lomb-Scargle technique favors the long period cycles. Note the detailed agreement. For example, the 26,000 - and 70,000 -yr peaks are present in both the Lomb-Scargle and singular value decomposition periodograms for Hole 701A, but the Lomb-Scargle peaks are not considered statistically significant.

that errors in the age picks used to convert depth to age are minor over a time scale of $500,000 \mathrm{yr}$. In the following discussions, all of the evolutive spectra make use of 500,000 -yr windows.

The Lomb-Scargle GRAPE density and magnetic susceptibility periodograms for Holes 699A, 701A, and 701C are shown in Figure 12. We will not discuss all of the peaks in all of the spectra; we simply wish to identify the major consistent peaks, those that are present in a number of spectra. The magnetic susceptibility spectra tend to have few short period peaks, far fewer than we see in the spectra for the other properties. The amplitude of the magnetic susceptibility vari- ations are also relatively small. The major peaks overall appear to be at about $37,000,122,000$, and $147,000 \mathrm{yr}$, with some scatter about those positions. There are, of course, a number of peaks in common for the spectra for the adjacent Holes 701A and 701C.

The results of the Kolmogorov-Smirnov test of similarity of the periodograms from Figure 12 are shown in Figures 13 and 14. The comparisons of the periodograms obtained for the GRAPE density and magnetic susceptibility (Fig. 13) are poor, even where there are similarities in the spectral peak positions, for example, at $127,000 \mathrm{yr}$ for Hole $701 \mathrm{~A}$ and $147,000 \mathrm{yr}$ for Hole $701 \mathrm{C}$. This suggests that there is a difference in the 


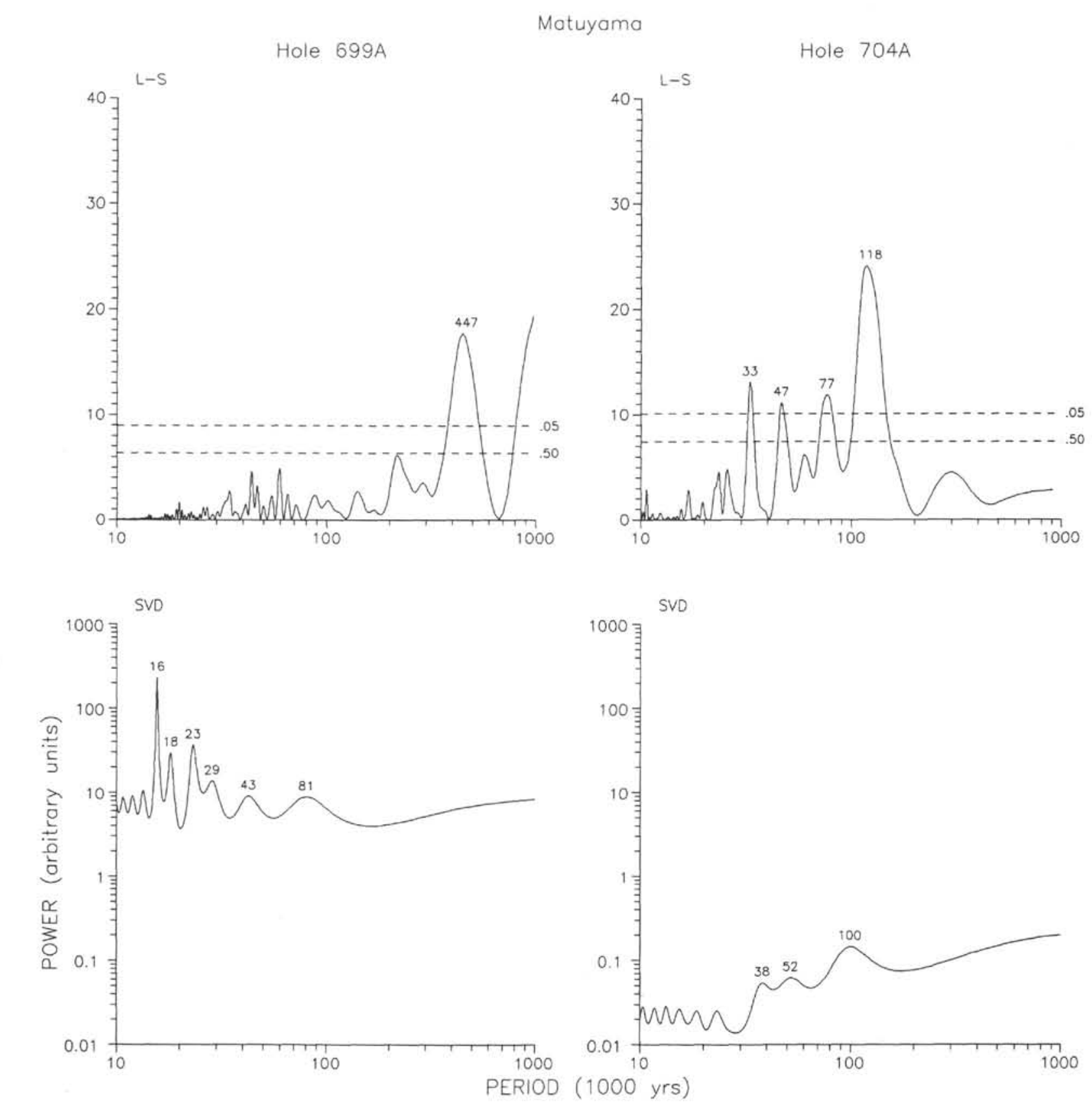

Matuyama

Figure 11. Lomb-Scargle and singular value decomposition maximum entropy magnetic susceptibility periodograms for Holes $699 \mathrm{~A}$ and $704 \mathrm{~A}$ for the Matuyama. Again, the singular value decomposition method yields the short period peaks whereas the Lomb-Scargle technique favors the long period cycles. The short period peaks are much more prevalent here, and there is a suppression of peaks for periods of $100,000 \mathrm{yr}$ and longer.

response of GRAPE density and magnetic susceptibility to orbital forcing at these three holes and/or a lack of significant concentrations of magnetic minerals, with a resulting low signal level that makes the identification of cyclicity in the magnetic susceptibility difficult. Figure 14 shows the hole-tohole comparison of the periodograms from Figure 12. Again, the spectra do not correlate well, suggesting spatial differences in response to orbital forcing and/or poor depth-to-age conversion. The latter case is likely in light of the dissimilarity of the spectra for the adjacent holes from Site 701. We note, however, that the Kolmogorov-Smirnov test for the GRAPE density for Holes 701A and 701C shows the most consistent degree of similarity. The lack of correlation for the magnetic susceptibility spectra could, as mentioned previously, be attributed to low signal levels, and the lack of spatial correlation between Sites 699 and 701 could be ascribed to spatial variability in the responses.

We have collected the spectra for Site 704, from Holes $704 \mathrm{~A}$ and 704B, separately. The Meteor Rise site was near the Polar Front and thus would be sensitive to small changes in the position of the front. In addition, the Quaternary section is over $100 \mathrm{~m}$ thick, as compared to approximately $20 \mathrm{~m}$ at Site 699 and approximately $40 \mathrm{~m}$ at Site 701 . Thus, the Quaternary at Site 704 is anomalously thick and positioned so as to record small changes in the Polar Front. There are a great many peaks (Fig. 15), some of which are in common with the spectra 

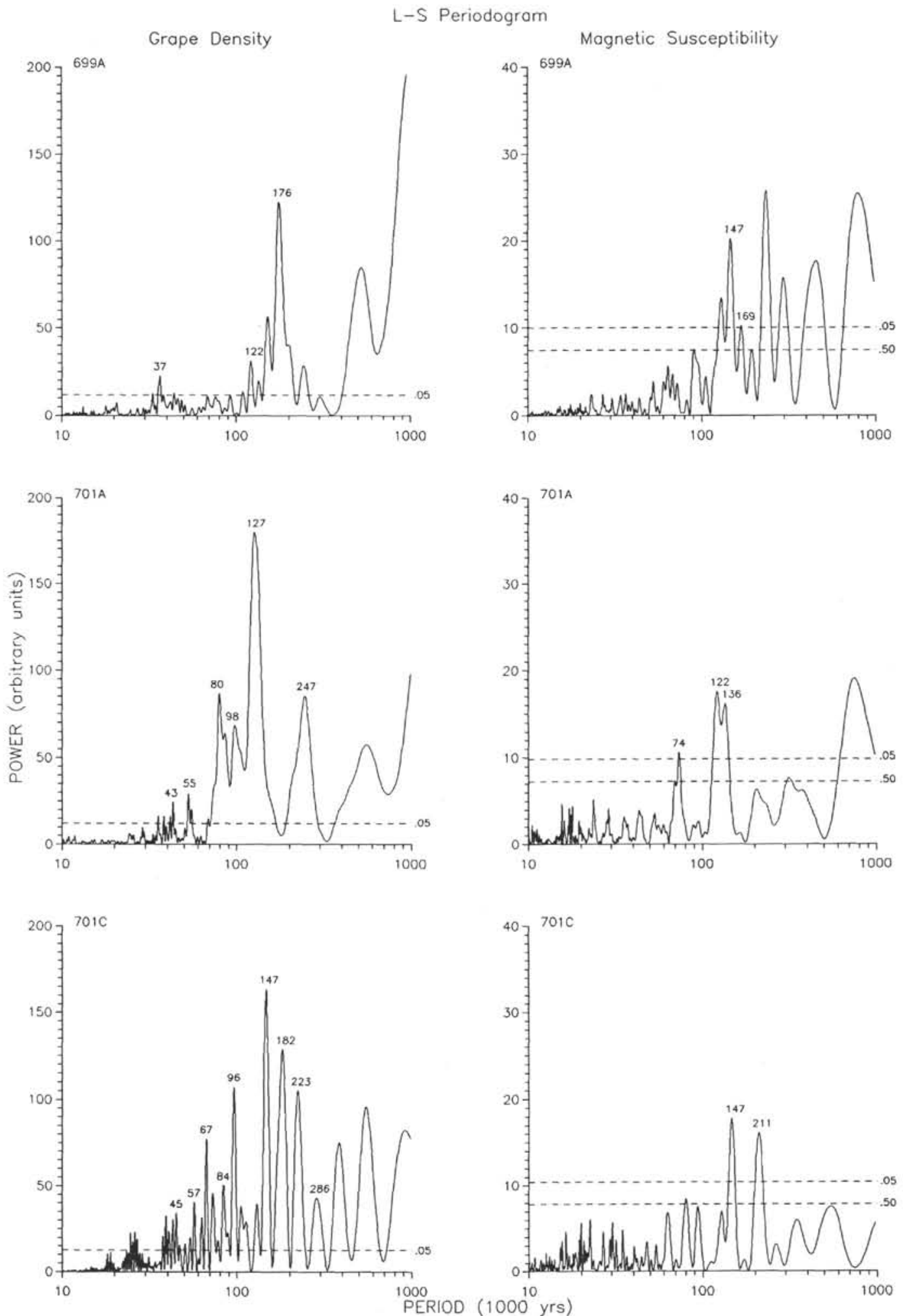

Figure 12. Lomb-Scargle periodograms for the GRAPE density and magnetic susceptibility for Holes 699A, 701A, and 701C. The great number of peaks is discussed in more detail in the text. 

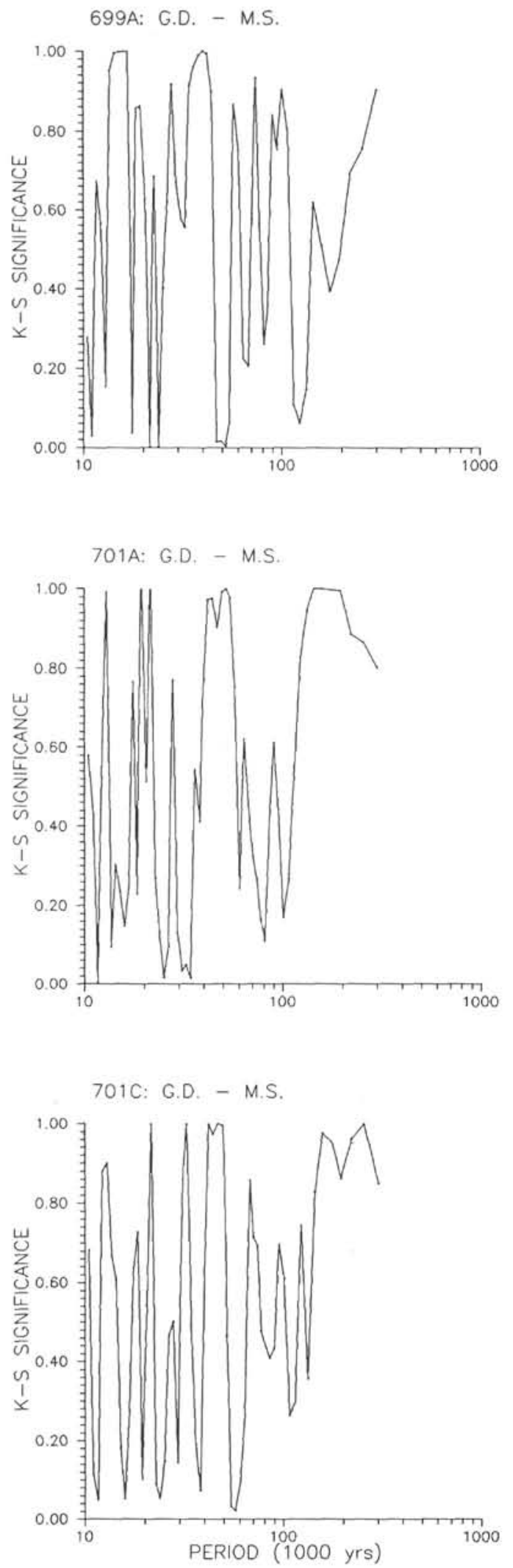

Figure 13. Kolmogorov-Smirnov similarity test for comparison of the physical-property response of magnetic susceptibility and GRAPE density at Holes 699A, 701A, and 701C. The poor KolmogorovSmirnov statistic throughout suggests a difference in response to orbital forcing of the two physical properties in question and/or a low signal content in the magnetic susceptibility. from the other sites. Not all of the significant peaks are labeled. A great many peaks are common to both Holes 704A and $704 \mathrm{~B}$, as might be expected, and the KolmogorovSmirnov similarity between the GRAPE density and the carbonate content is high in the period bands of interest for both holes (Fig. 16). The magnetic susceptibility data have a low signal content, as mentioned previously, and are restricted to the Matuyama period $(0.73 \mathrm{Ma}$ in age). The magnetic susceptibility data thus cannot be directly compared with the GRAPE and carbonate data sets, which cover the whole of the Quaternary.

The Hole 704A data show peaks slightly offset from those in Hole 704B, which may be related to the depth-to-age conversion. If the inferred sedimentation rates for the two holes are slightly off, then we would see the peaks offset by a constant multiplicative factor, equivalent to the ratios of the sedimentation rates, which on a logarithmic period scale would be a constant offset. Thus, the peak at $92,000 \mathrm{yr}$ in the Hole $704 \mathrm{~A}$ carbonate spectrum may be closer to $105,000 \mathrm{yr}$, or the peak at about $91,000 \mathrm{yr}$ in the Hole 704A GRAPE spectrum may be closer to $99,000 \mathrm{yr}$, which would then be consistent with the Hole 704B results. If the peaks are shifted by a multiplicative factor in this manner to bring the $92,000-\mathrm{yr}$ carbonate peak to $105,000 \mathrm{yr}$, then, in fact, we do see an improvement in the Kolmogorov-Smirnov statistic for carbonate, but there is no improvement in the GRAPE statistical similarity (Fig. 17).

Some of the problems in the comparison of the spectra from Holes $704 \mathrm{~A}$ and $704 \mathrm{~B}$ may be related to the sparser sampling interval for carbonate in Hole 704B and to significant gaps in core recovery in both holes. In order to attempt to compensate for this, a composite Site 704 section was constructed (Froelich et al., this volume), and the Lomb-Scargle periodogram was computed for the composite section for the whole of the Quaternary (0-1.66 Ma B.P., Fig. 18) and for the Brunhes (0-0.73 Ma B.P., Fig. 18) and Matuyama (0.73-1.66 Ma B.P., Fig. 18) periods separately. We see a large improvement in the Kolmogorov-Smirnov statistical similarity between the GRAPE and carbonate content when the composite section is compared to Hole 704A (Fig. 19), both at longer periods $(100,000 \mathrm{yr})$ and at moderate periods $(20,000$ to 40,000 $\mathrm{yr})$. The split peak with a period near $100,000 \mathrm{yr}$ that is present in the spectra for both Holes 704A and 704B appears to coalesce into one peak near $100,000 \mathrm{yr}$ (top plot, Fig. 18). Significant peaks are also present in the range 19,000 to 26,000 $\mathrm{yr}$, near $40,000 \mathrm{yr}$, and at about $410,000 \mathrm{yr}$ (top plot of Fig. 18; top right-hand plot of Fig. 19). We suggest that these spectral peaks are representative of Milankovitch cycles, which would be expected at $23,000,41,000,100,000$, and $410,000 \mathrm{yr}$ (e.g., Berger, 1988), and are similar to peaks noted in Figure 1.

In addition to the Milankovitch spectral peaks, consistent peaks appear to be present at about $11,000,15,000,31,000$, $70,000,77,000,140,000$, and $200,000 \mathrm{yr}$. There may be other peaks, but they are not consistently present throughout the whole of the Quaternary. How may we explain the additional peaks? We could invoke a mixing of the peaks in the analysis, but we cannot obtain all of the prominent peaks by simple linear combinations of the Milankovitch peaks. Wild fluctuations in the sedimentation rate could also create some extraneous peaks, but this would not explain why the peaks form continuous trends in the evolutive spectra. If, on the other hand, we accept that the atmosphere-ocean system is nonlinear then the extra peaks may be readily explained. As we stated in the "Introduction," an examination of the full set of Navier-Stokes and thermodynamic equations that govern the atmosphere and oceans should convince one of the inherent nonlinearity of the system. The system is nonlinear not just 

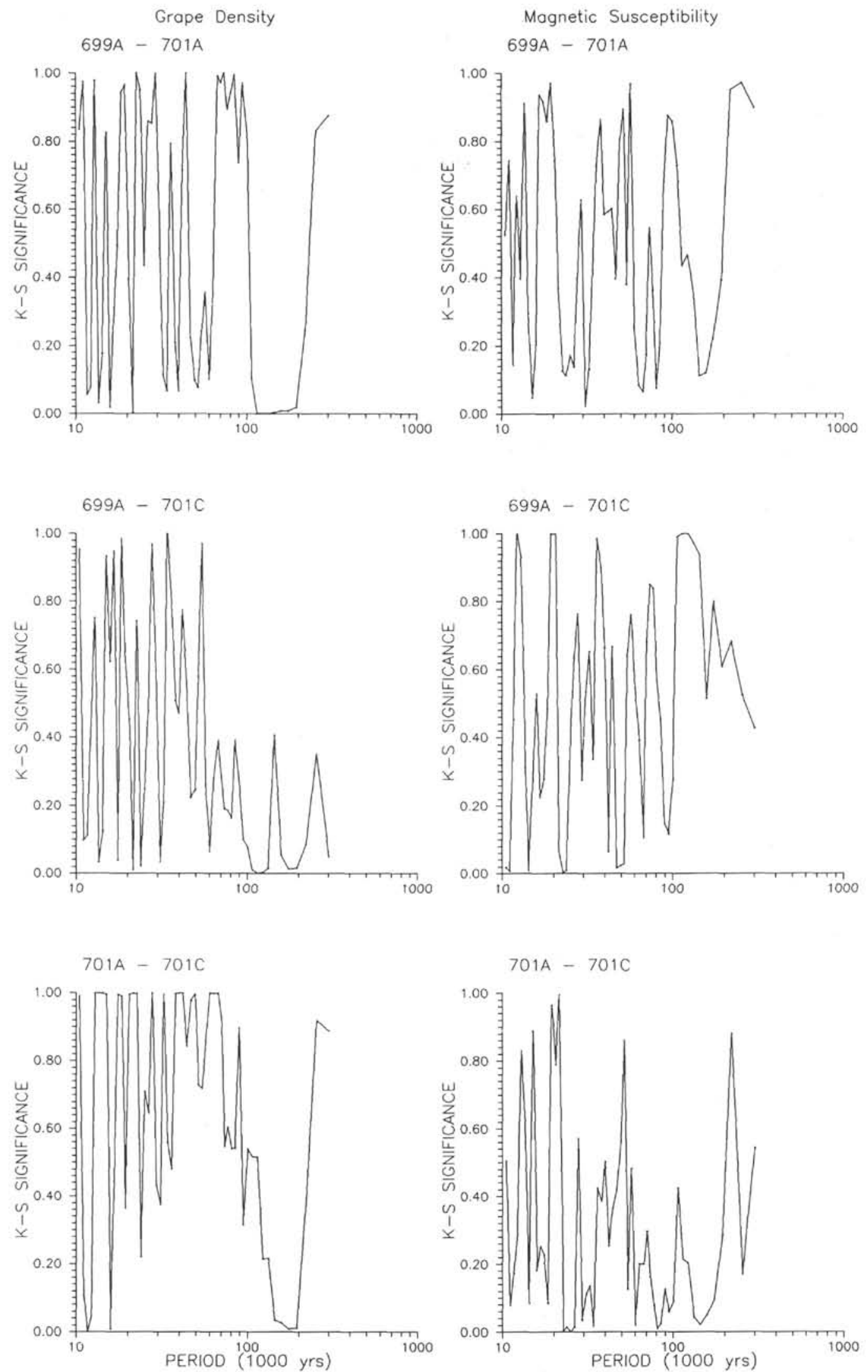

Figure 14. Kolmogorov-Smirnov similarity test for comparison of the site dependency of the physical-property response at Holes 699A, 701A, and 701C. In this case, the poor Kolmogorov-Smirnov statistic suggests a site-dependent response and/or poor depth-to-age conversion. 
Hole $704 \mathrm{~A}$
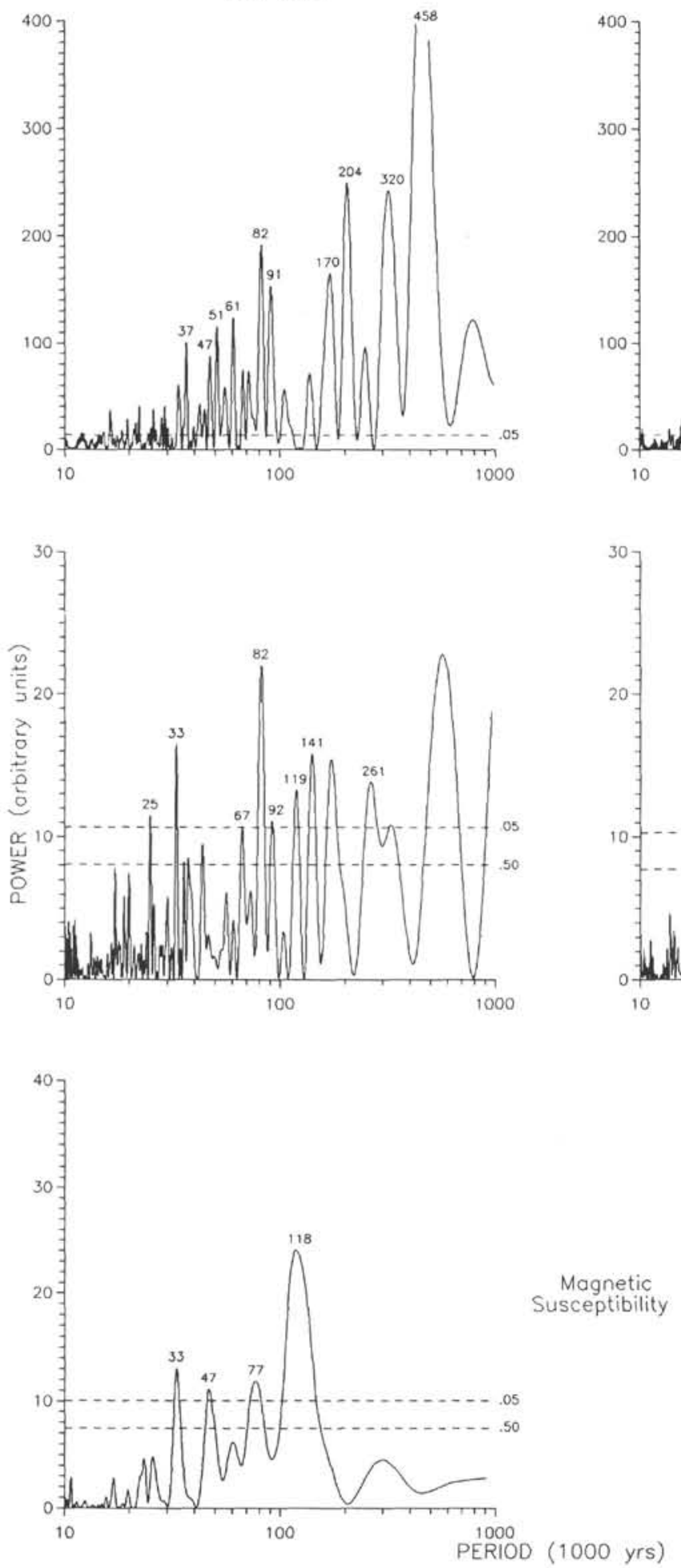

Hole 704B
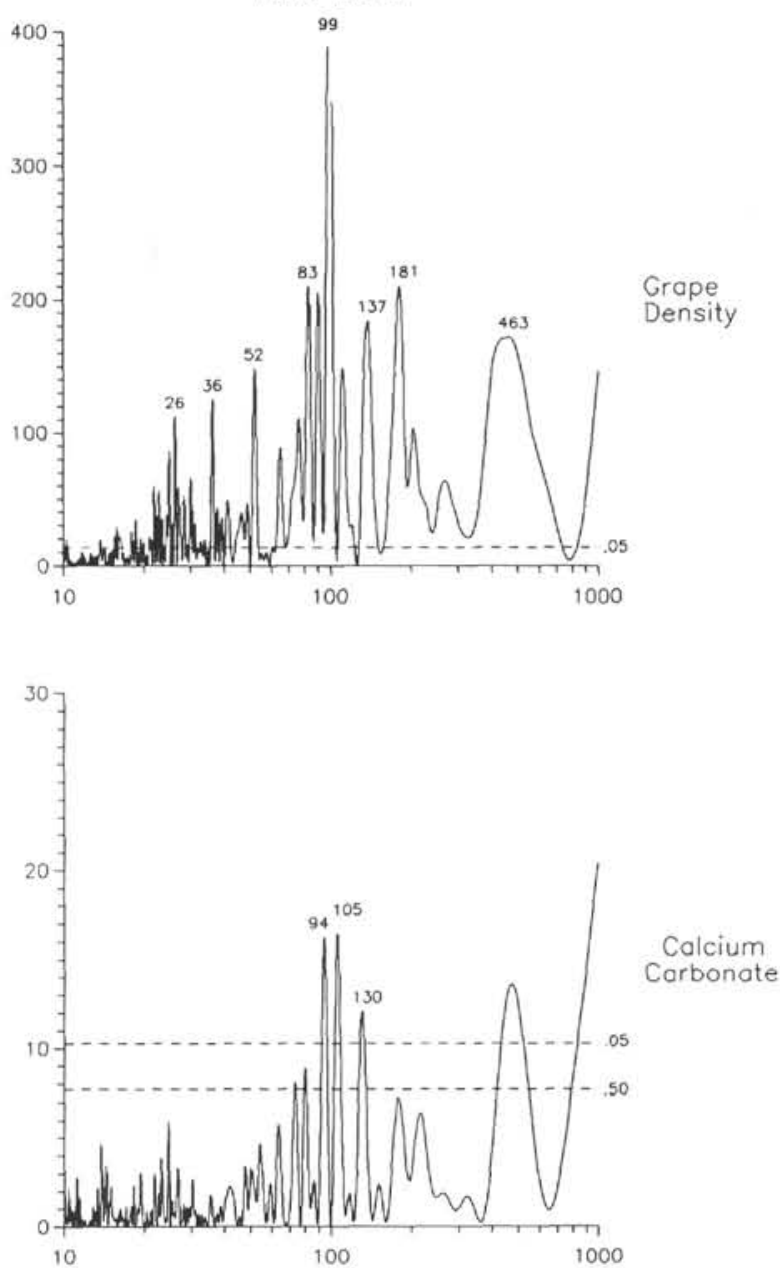

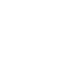



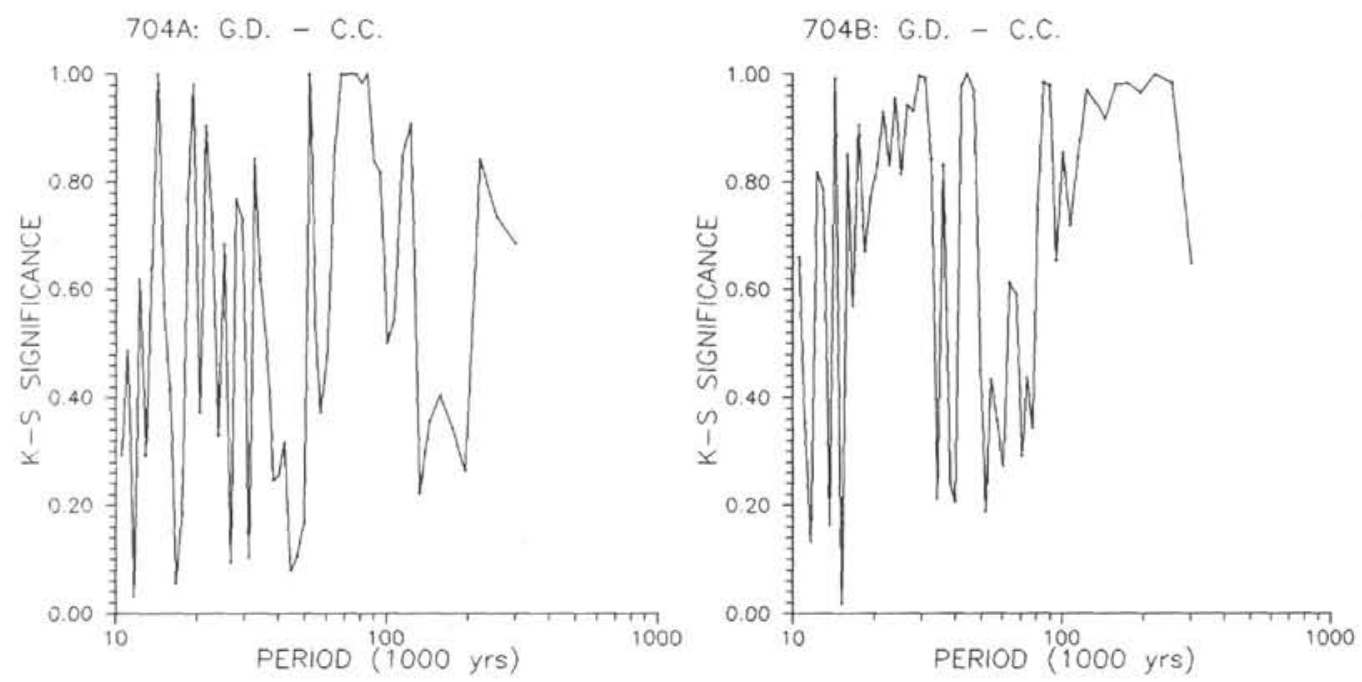

Figure 16. Kolmogorov-Smirnov similarity test between GRAPE density and carbonate content for Holes $704 \mathrm{~A}$ and $704 \mathrm{~B}$.

temporally but spatially as well. The nonlinearities do not disappear when averaged over time.

An example of a simple nonlinear system response, $R$, with a natural frequency, $\Phi$, is represented by the equation

$$
\begin{aligned}
\frac{d^{2} R}{d t^{2}}+\Phi^{2} R+\alpha R^{2} & +\beta R^{3}+\ldots=A \cos \Omega_{1} t \\
& +B \cos \Omega_{2} t .
\end{aligned}
$$

This model is simply the equation of a nonlinear harmonic oscillator without damping driven by more than one periodic input. The model is somewhat analogous to the harmonic oscillator ice sheet model of Le Treut and Ghil (1983) used to investigate changes in ice mass and global temperature. If a nonlinear system is driven at two frequencies, $\Omega_{1}$ and $\Omega_{2}$, the system will have responses not only at those frequencies, but also at the harmonics, $2 \Omega_{1}$ and $2 \Omega_{2}$, the subharmonics, $1 / 2 \Omega_{1}$ and $1 / 2 \Omega_{2}$, and the linear combinations, $\Omega_{1}+\Omega_{2}$ and $\Omega_{1}-\Omega_{2}$, for the $R^{2}$ term, and at the harmonics, $3 \Omega_{1}$ and $3 \Omega_{2}$, the subharmonics, and the linear combinations, $2 \Omega_{1} \pm \Omega_{2}$ and $2 \Omega_{1}$ $\pm \Omega_{2}$ for the $R^{3}$ term, and so on (Marion, 1970).

The nonlinear spectral peaks that might be expected from $19,000,23,000-, 41,000-, 100,000-$, and 410,000-yr Milankovitch forcing frequencies are listed in Table 1 . Note the great proliferation of spectral peaks arising from a nonlinear response. Many of the peaks can arise from more than one source, and are at or very near those that have been consistently identified in the spectral analyses, of which there are a significant number. We, of course, can carry on to higher orders, but we need not even resort to order 3 nonlinearity to explain the vast majority of the observed spectral peaks. The relative amplitudes of the resulting frequencies from this response model depend on the relative amplitudes of the input frequencies, the degree of nonlinearity in the system, and the proximity of the driving frequencies to the natural frequency of the system.

Previous studies have suggested that the climatic response changes with time, in particular that the $100,000-\mathrm{yr}$ cycle is most prominent in the last $700,000 \mathrm{yr}$ and not very prevalent prior to about 0.7 Ma B.P. (e.g., Berger, 1988; Pestiaux and Berger, 1984). We have split our data sets using the Brunhes/ Matuyama boundary as the demarcation. It is interesting to note that the Brunhes/Matuyama boundary was used as one of the age picks for Hole 704A, but not for Hole 704B or for the Site 704 composite section (Froelich et al., this volume). The Lomb-Scargle results for the Site 704 composite section are shown in Figures 18 and 19 for the GRAPE density and carbonate content data, and the spectra for the Brunhes and Matuyama look different. The spectra for the whole of the Quaternary are shown at the top for comparison. Note the lack of statistical similarity at longer periods $(100,000 \mathrm{yr})$ and the greater number of shorter period peaks in the Matuyama as compared with the Brunhes, which is consistent with previous studies. Statistically similar peaks appear in the Brunhes at about $12,000,54,000,75,000,100,000,190,000$, and $400,000 \mathrm{yr}$, with numerous peaks in the range from 23,000 to $46,000 \mathrm{yr}$ (middle part of Figs. 18 and 19). A great many statistically similar peaks are present in the Matuyama, but the similarity is more discrete and is clustered at shorter periods (bottom, Fig. 19). The strongest Matuyama peaks occur at about $10,000,14,000,16,000,19,000,24,000,50,000$, $70,000,87,000,100,000$, and $128,000 \mathrm{yr}$ and in the range from 32,000 to $40,000 \mathrm{yr}$.

The Lomb-Scargle evolutive spectra present a similar picture (Fig. 20) for the carbonate content alone. The 500,000 $\mathrm{yr}$ windows were rolled along every $50,000 \mathrm{yr}$, so there was usually significant window overlap except in the case of large data gaps. The Lomb-Scargle evolutive spectra for the Site 704 carbonate content are compared with the Lomb-Scargle periodograms for the whole of the Quaternary. The strongest change near the Brunhes/Matuyama boundary is apparent for the Hole 704A record (top, Fig. 20), where the Brunhes/ Matuyama boundary is one of the age picks, but is still noticeable in the Site 704 composite spectra with the loss of a clear peak near $100,000 \mathrm{yr}$ and the appearance of shorter period energy. Curiously, the composite spectra, both evolutive and for the whole of the Quaternary, have peaks near $200,000 \mathrm{yr}$, unlike either Hole 704A or Hole 704B.

The carbonate content sampling in Hole 704B was much less frequent than in Hole $704 \mathrm{~A}$, so that the number of resolved periods is less, as expected. In addition, the Hole 704B evolutive Lomb-Scargle periodogram shows what appears to be a migration of a peak from near $100,000 \mathrm{yr}$ to about $50,000 \mathrm{yr}$ and back again. Such a trend does not appear in the Hole 704A data. We may simply be seeing two peaks appearing in the Hole 704B data, but not at the same time, as the sampling rate within the window varies. 

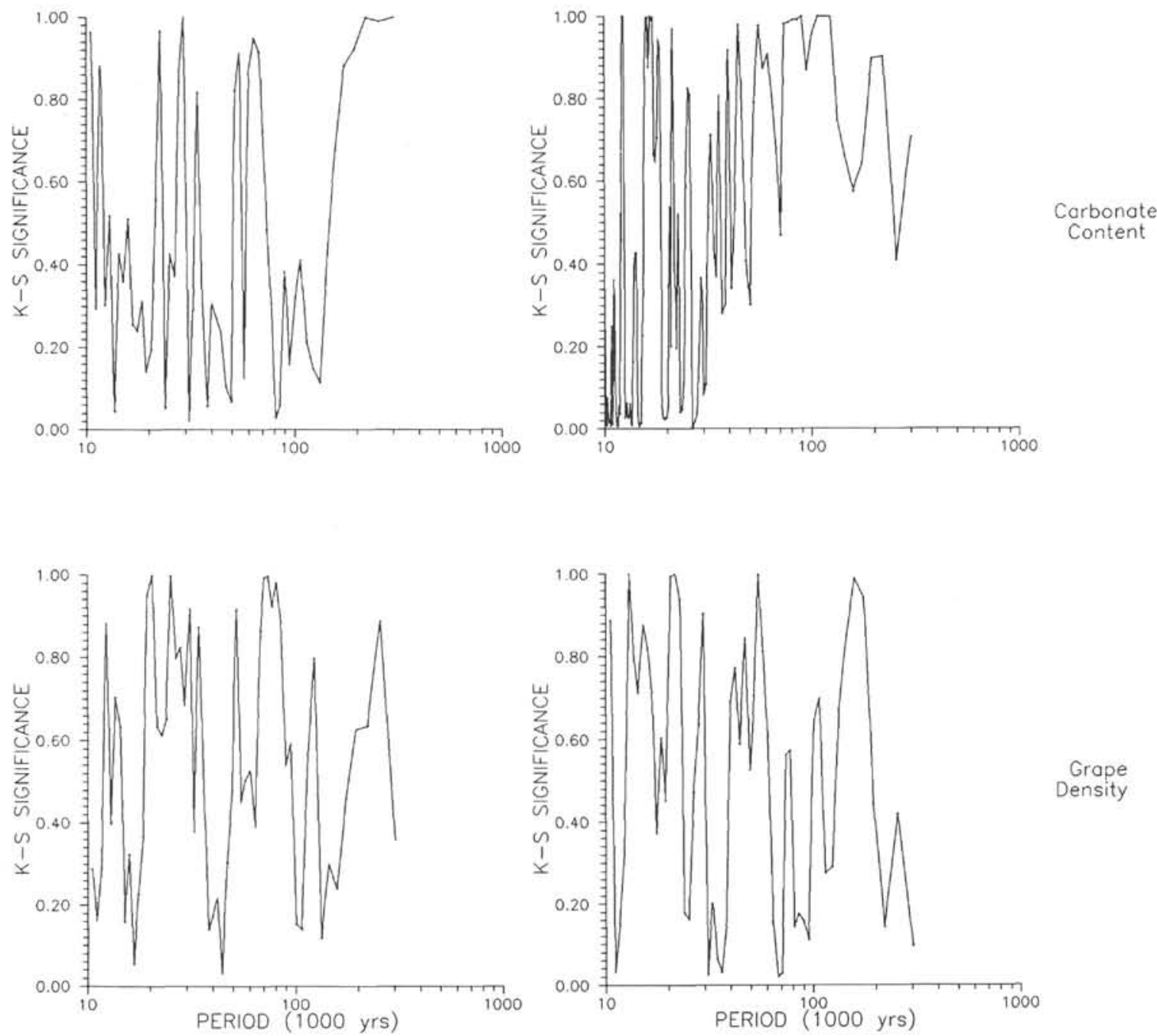

Figure 17. Kolmogorov-Smirnov similarity test for comparison of the site dependence of the physical-property response from Holes 704A and 704B. Multiplying the sedimentation rate for Hole 704A so that the peaks near $100,000 \mathrm{yr}$ in the carbonate content spectra from the two holes coincide results in a marked improvement in the Kolmogorov-Smirnov statistic, suggesting a slight problem in the depth-to-age conversion in one of the holes.

\section{CONCLUSIONS}

We have found evidence for Milankovitch cycles in the spectral analysis of physical-property data from Sites 699, 701, and 704 in the subantarctic South Atlantic. At the same time, we have encountered a number of other peaks that may be explained in terms of a nonlinear system response. If a nonlinear system is driven using two or more driving frequencies, then spectral peaks occur not only at the driving frequencies but also at linear combinations, harmonics, and subharmonics of the driving frequencies. The additional peaks we have found can be explained in this way as linear combinations, harmonics, and subharmonics of the Milankovitch frequencies.

When the data are analyzed for the Brunhes and Matuyama periods separately, we do note two important differences:

1. There appears to be a greater influence of shorter period cycles in the Matuyama than in the Brunhes.
2. The 100,000 -yr period is prominent in the Brunhes but is markedly less apparent in the Matuyama, which is consistent with earlier studies that have indicated that the $100,000-\mathrm{yr}$ cycle was prominent during the last $0.7 \mathrm{Ma}$.

The next stage of the research is to analyze the data from the rest of the Cenozoic and to compare our data from a subpolar region with that gathered from' polar, other subpolar, subtropical, and tropical regions so that we may examine the response across a range of geographic regions and geological periods.

\section{ACKNOWLEDGMENTS}

DCN acknowledges the support of the Natural Sciences and Engineering Research Council of Canada through a Collaborative Special Project grant. SFB acknowledges the support of NSERC through a Postgraduate Scholarship. We thank one anonymous reviewer for some careful and detailed comments. 


\section{REFERENCES}

Arthur, M. A., Dean, W. E., Bottjer, D., and Scholle, P. A., 1984 Rhythmic bedding in Mesozoic-Cenozoic pelagic carbonate sequences: the primary and diagenetic origin of Milankovitch-like cycles. In Berger, A., Imbrie, J., Hays, J., Kukla, G., and Saltzman, B. (Eds.), Milankovitch and Climate (pt. 1): Dordrecht (D. Reidel), 191-222.

Beauchamp, K. G., 1975. Walsh Functions and Their Applications: New York (Academic Press).

Berger, A., 1988. Milankovitch theory and climate. Rev. Geophys., 26:624-657.

Berger, A., Imbrie, J., Hays, J., Kukla, G., and Saltzman, B., 1984. Milankovitch and Climate: NATO ASI Ser., Ser. C, 126.

Bloomer, S. F., 1989. Nonlinear response to Milankovitch cycles in the subantarctic South Atlantic [M.S. thesis]. Univ. of Waterloo.

Bloomer, S. F., and Nobes, D. C., 1989. Late Cenozoic climatic variations: nonlinear response to Milankovitch cycles [paper presented at the Univ. Michigan Geol. Sci. Sesquicentennial Symp., Ann Arbor, MI].

Bloomfield, P., 1975. Fourier Analysis of Time Series: New York (Wiley).

Borehole Research Group, 1986. Wireline Logging Manual (2nd ed.): Palisades, NY (Lamont-Doherty Geological Observatory, Columbia Univ.).

Boyce, R. E., 1976. Definitions and laboratory techniques of compressional sound velocity parameters and wet-water content, wet-bulk density, and porosity parameters by gravimetric and gamma ray attenuation techniques. In Schlanger, S. O., Jackson, E. D., et al., Init. Repts. DSDP, 33: Washington (U.S. Govt. Printing Office), 931-958.

Burg, J. P., 1975. Maximum entropy spectral analysis [Ph.D. dissert.]. Stanford Univ.

Chaghagi, F. S., 1985. Time Series Package (TSPACK): Berlin (Springer-Verlag).

Conover, W. J., 1980. Practical Nonparametric Statistics: New York (Wiley).

Dean, W. E., and Gardner, J. V., 1984. Cyclic variations in calcium carbonate and organic carbon in Miocene to Holocene sediments, Walvis Ridge, South Atlantic Ocean. In Berger, A., Imbrie, J., Hays, J., Kukla, G., and Saltzman, B. (Eds.), Milankovitch and Climate (pt. 1): Dordrecht (D. Reidel), 265-266.

deMenocal, P., and ODP Leg 117 Shipboard Scientific Party, 1988. Analysis of magnetic susceptibility data, ODP Leg 117 [paper presented at the Am. Geophys. Union Annual Fall Meeting, San Francisco, CA].

Friere, S.L.M., and Ulrych, T. J., 1988. Application of singular value decomposition to vertical seismic profiling. Geophysics, 53:778-785.

Horne, J. H., and Baliunas, S. L., 1986. A prescription for period analysis of unevenly sampled time series. Astrophys. J., 302:757-763.

Hovan, S. A., Rea, D. K., Pisias, N. G., and Shackleton, N. J., 1989. A direct link between the China loess and marine $\delta^{18} \mathrm{O}$ records: aeolian flux to the North Pacific. Nature, 340:296-298.

Imbrie, J., Hays, J. D., Martinson, D. G., McIntyre, A., Mix, A. C., Morley, J. J., Pisias, N. G., Prell, W. L., and Shackleton, N. J., 1984. The orbital theory of Pleistocene climate: support from a revised chronology of the marine $\delta^{18} \mathrm{O}$ record. In Berger, A., Imbrie, J., Hays, J., Kukla, G., and Saltzman, B. (Eds.), Milankovitch and Climate (pt. 1): Dordrecht (D. Reidel), 269-305.

Kanasewich, E. R., 1981. Time Sequence Analysis in Geophysics (3rd ed.): Edmonton, Alberta (Univ. Alberta Press).

Le Treut, H., and Ghil, M., 1983. Orbital forcing, climatic interactions, and glaciation cycles. J. Geophys. Res., 88:5167-5190.

Lomb, N. R., 1976. Least-squares frequency analysis of unequally spaced data. Astophys. Space Sci., 39:447-462.

Marion, J. B., 1970. Classical Dynamics of Particles and Systems (2nd ed.): New York (Academic Press).

Menke, W., 1985. Geophysical Data Analysis: Discrete Inverse Theory: Orlando, FL (Academic Press).

Minami, K., Kawata, S., and Minami, S., 1985. Superresolution of Fourier transform spectra by autoregressive model fitting with singular value decomposition. Appl. Opt., 24:162-167.

Pestiaux, P., and Berger, A., 1984. An optimal approach to the spectral characteristics of deep-sea climatic records. In Berger,
A., Imbrie, J., Hays, J., Kukla, G., and Saltzman, B. (Eds.), Milankovitch and Climate (pt. 1): Dordrecht (D. Reidel), 417-445.

Pollard, D., 1982. A simple ice sheet model yields realistic $100 \mathrm{kyr}$ glacial cycles. Nature, 296:334-338.

Press, W. H., Flannery, B. P., Teukolsky, S. A., and Vetterling, W. T., 1986. Numerical Recipes: Cambridge (Cambridge Univ. Press).

Press, W. H., and Teukolsky, S. A., 1988. Search algorithms for weak periodic signals in unevenly spaced data. Comp. Phys., 2:79-82.

Ruddiman, W. F., Shackleton, N. J., and McIntyre, A., 1986. North Atlantic sea-surface temperatures for the last 1.1 million years. In Summerhays, C. P., and Shackleton, N. J. (Eds.), North Atlantic Paleoceanography. Geol. Soc. Am. Spec. Publ., 21:155-173.

Scargle, J. D., 1982. Aspects of spectral analysis of unevenly spaced data. Astrophys. J., 263:835-853.

Shipboard Scientific Party, 1988a. Explanatory Notes. In Ciesielski, P. F., Kristoffersen, Y., et al., Proc. ODP, Init. Repts., 114 College Station, TX (Ocean Drilling Program), 3-22. 1988b. Preliminary results of subantarctic South Atlantic Leg 114 Ocean Drilling Program. In Ciesielski, P. F., Kristoffersen, Y., et al., Proc. ODP, Init. Repts., 114: College Station, TX (Ocean Drilling Program), 797-803. 1988c. Site 699. In Ciesielski, P. F., Kristoffersen, Y., et al., Proc. ODP, Init. Repts., 114: College Station, TX (Ocean Drilling Program), 151-254. 1988d. Site 701. In Ciesielski, P. F., Kristoffersen, Y., et al., Proc. ODP, Init. Repts., 114: College Station, TX (Ocean Drilling Program), 363-482.

1988e. Site 704. In Ciesielski, P. F., Kristoffersen, Y., et al., Proc. ODP, Init. Repts., 114: College Station, TX (Ocean Drilling Program), 621-796.

Walsh, J. T., 1923. A closed set of normal orthogonal functions. Am. J. Math., 45:5-24.

Wigley, T.M.L., 1976. Spectral analysis and the astronomical theory of climatic change. Nature, 264:629-631.

Date of initial receipt: 3 April 1989

Date of acceptance: 4 January 1990 Ms 114B-161

Table 1. Harmonic, subharmonic, and linear combinations of the $19,000-, 23,000-, 41,000-, 100,000-$, and 410,000-yr Milankovitch cycle peaks arising in the response of a nonlinear harmonic oscillator.

\begin{tabular}{|c|c|c|c|c|}
\hline \multirow{3}{*}{$\begin{array}{c}\text { Period } \\
(1000 \text { yr) }\end{array}$} & \multicolumn{4}{|c|}{ Harmonic and subharmonic } \\
\hline & \multicolumn{2}{|c|}{ Harmonic } & \multicolumn{2}{|c|}{ Subharmonic } \\
\hline & Order 2 & Order 3 & Order 2 & Order \\
\hline 19 & 38 & 57 & 9.5 & 6.3 \\
\hline 23 & 46 & 69 & 11.5 & 7.7 \\
\hline 41 & 82 & 123 & 20.5 & 14 \\
\hline 100 & 200 & 300 & 50 & 33 \\
\hline 410 & 820 & 1230 & 205 & 137 \\
\hline \multirow{2}{*}{$\begin{array}{l}\text { Period } \\
(1000 \mathrm{yr})\end{array}$} & \multicolumn{4}{|c|}{ Linear Combination } \\
\hline & \multicolumn{2}{|c|}{ Order 2} & \multicolumn{2}{|l|}{ Order 3} \\
\hline 19,23 & \multicolumn{2}{|c|}{$10.4,109$} & \multicolumn{2}{|c|}{$6.7,7.2,16,29$} \\
\hline 19,41 & \multirow{2}{*}{\multicolumn{2}{|c|}{$\begin{array}{l}13,35 \\
16,23.5\end{array}$}} & \multicolumn{2}{|c|}{$7.7,10,12.4,260$} \\
\hline 19,100 & & & \multicolumn{2}{|c|}{$8.7,10.5,14,31$} \\
\hline 19,410 & \multicolumn{2}{|c|}{18,20} & $9.3,9.7,17.4$, & 21 \\
\hline 23,41 & \multicolumn{2}{|c|}{15,52} & \multicolumn{2}{|c|}{$\begin{array}{l}9.3,9.7,17.4,21 \\
9,11,16,189\end{array}$} \\
\hline 23,100 & \multicolumn{2}{|c|}{19,30} & \multicolumn{2}{|c|}{$10.3,13,16,43$} \\
\hline 23,410 & \multirow{2}{*}{\multicolumn{2}{|c|}{$\begin{array}{l}22,24 \\
29,69.5\end{array}$}} & \multicolumn{2}{|c|}{$11.2,11.8,21,26$} \\
\hline 41,100 & & & & \\
\hline 41,410 & \multicolumn{2}{|c|}{37,46} & \multicolumn{2}{|c|}{$20,22,34,51$} \\
\hline 100,410 & \multicolumn{2}{|c|}{80,132} & \multicolumn{2}{|c|}{$45,57,67,195$} \\
\hline
\end{tabular}




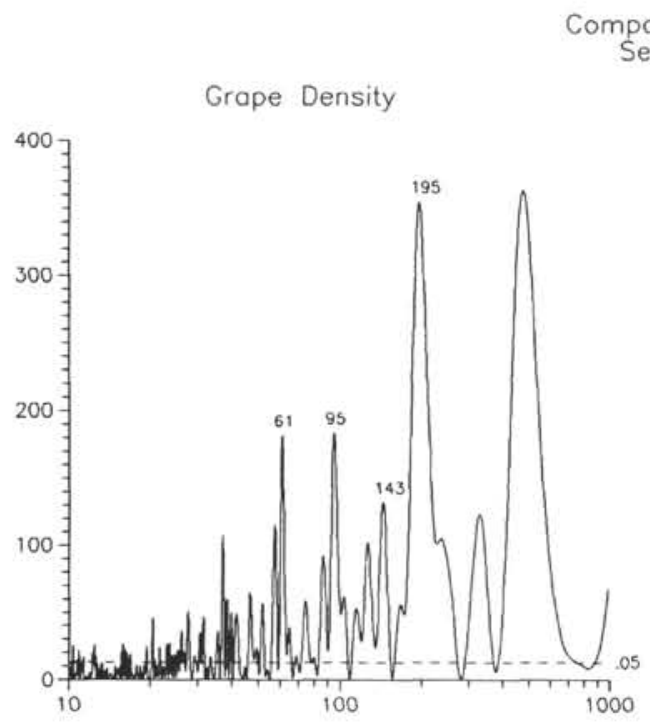

$$
\begin{aligned}
& \text { mposite } 704 \\
& \text { Section }
\end{aligned}
$$
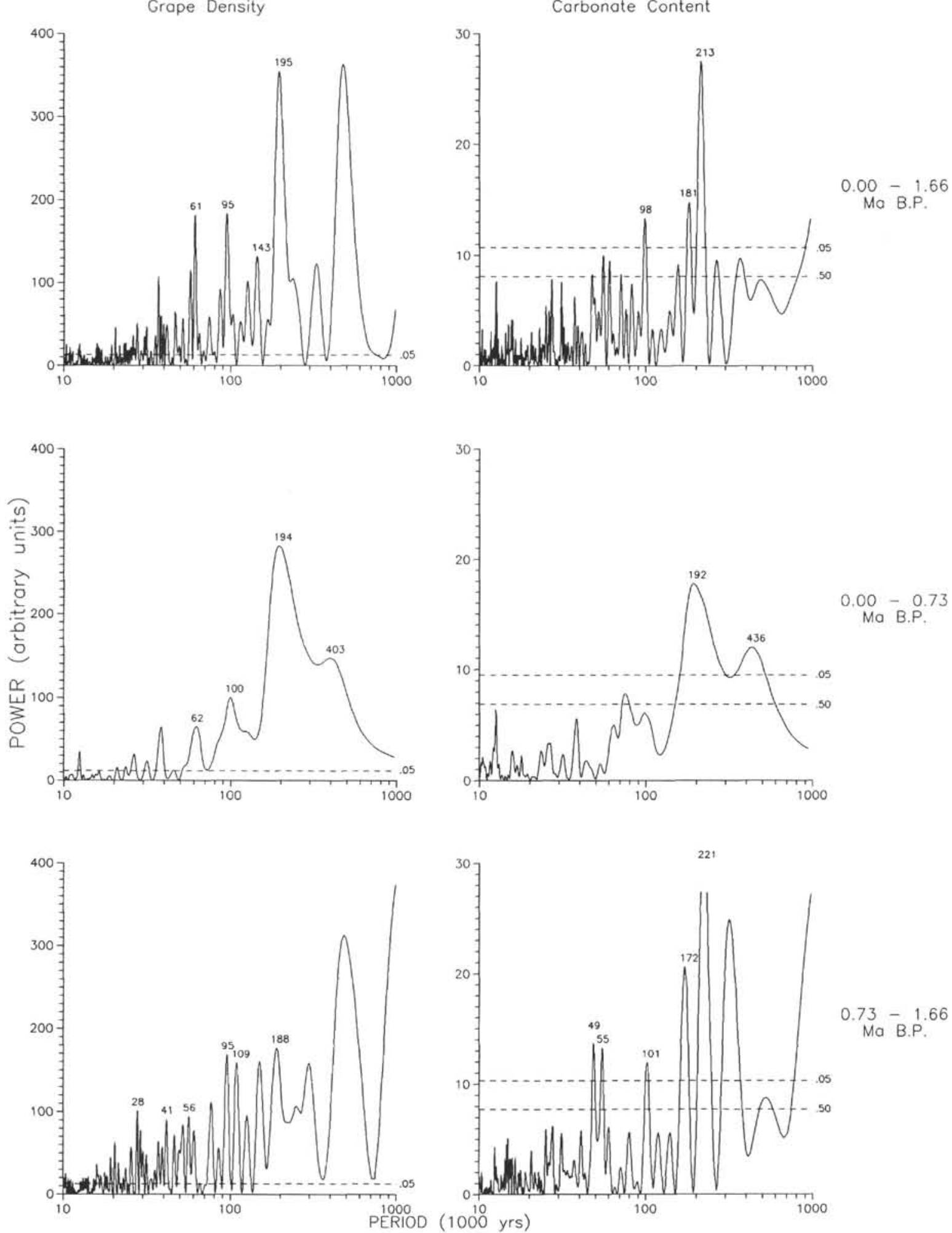

Figure 18. Lomb-Scargle periodograms for the Site 704 composite section GRAPE density and carbonate content for the whole of the Quaternary (top), the Brunhes (middle), and the Matuyama (bottom). The character of the spectra changes from the Brunhes to the Matuyama, with an enhancement of the short period peaks in the Matuyama, particularly in the carbonate content spectra. 
Hole 704A

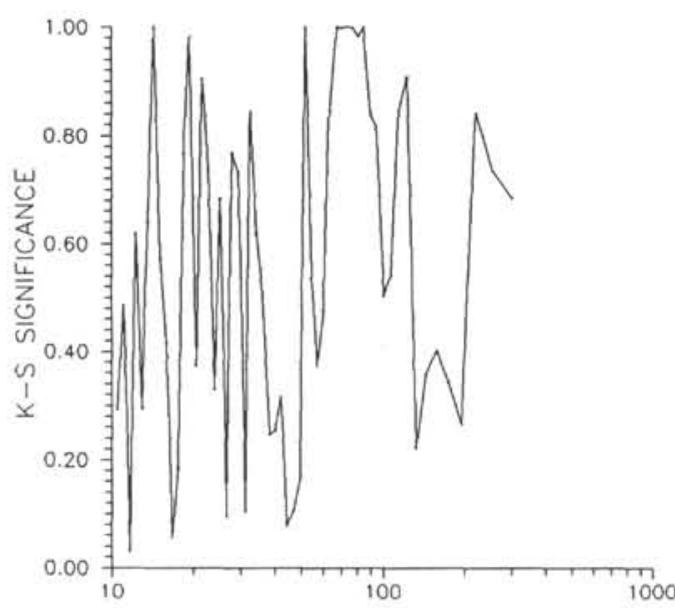

Site 704 Composite

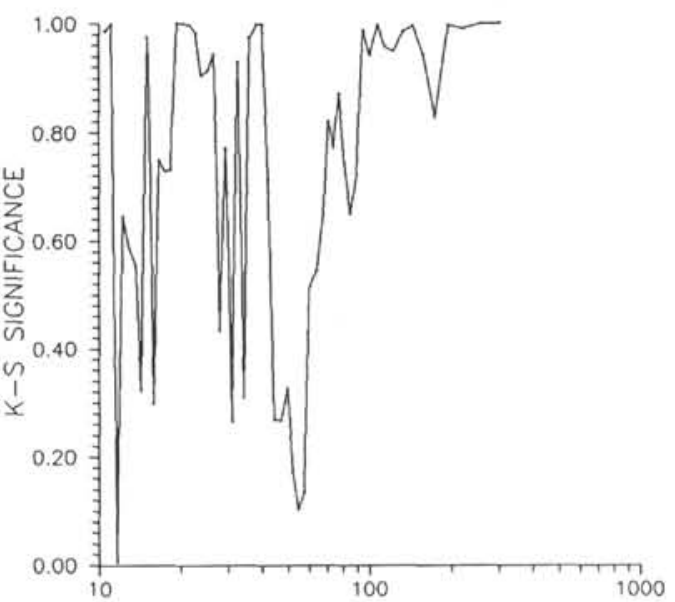

$0.00-1.66$

$\mathrm{Ma}$ B.P.
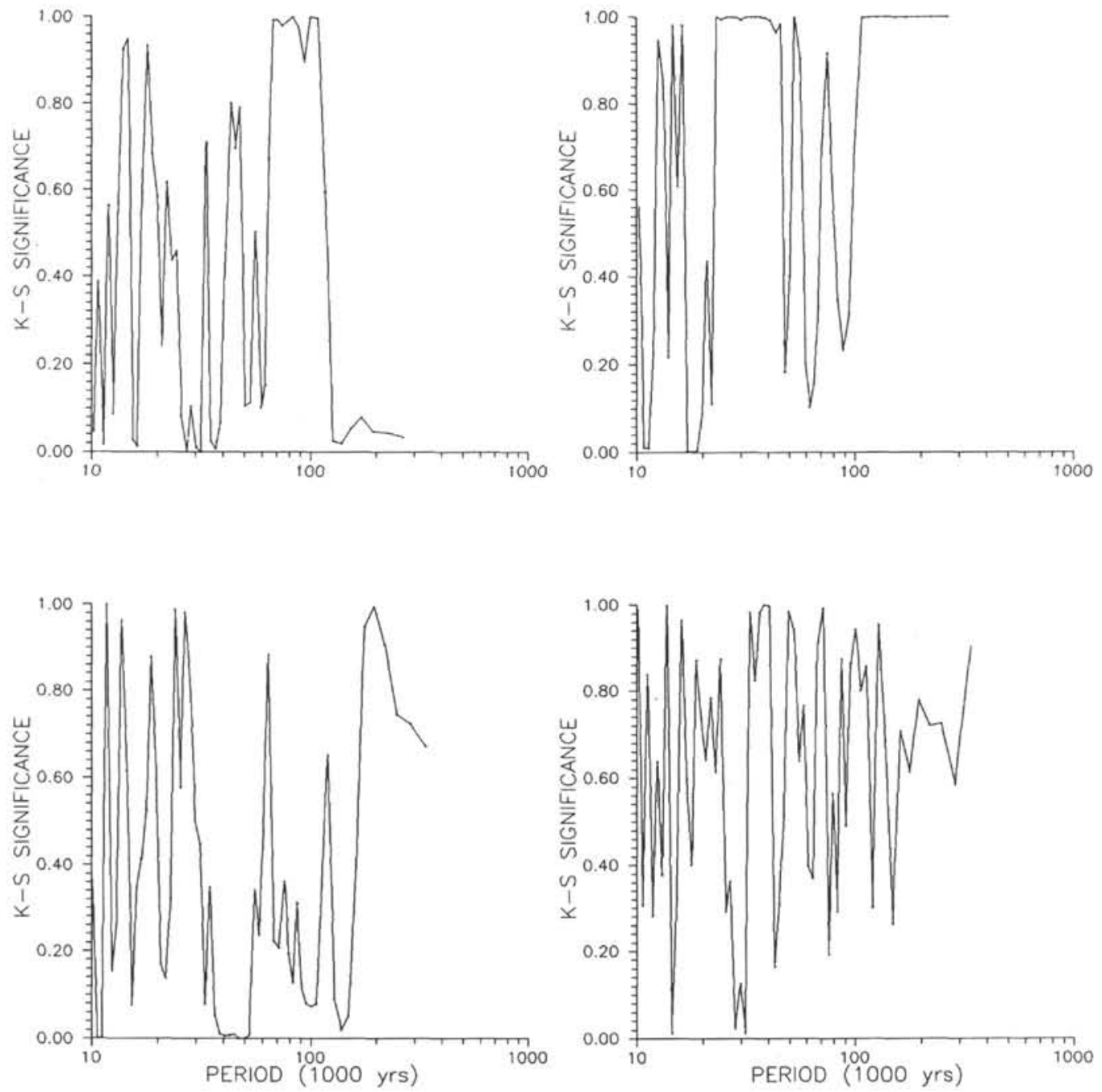

Figure 19. Kolmogorov-Smirnov similarity test for comparison of the physical-property response of carbonate content and GRAPE density at the Site 704 composite section and Hole 704A for the Brunhes, Matuyama, and the entire Quaternary. Note the high significance of power distribution similarity around $100,000 \mathrm{yr}$ for both Hole $704 \mathrm{~A}$ and the Site 704 composite section for the Brunhes and the entire Quaternary. 
Evolutive $L-S$
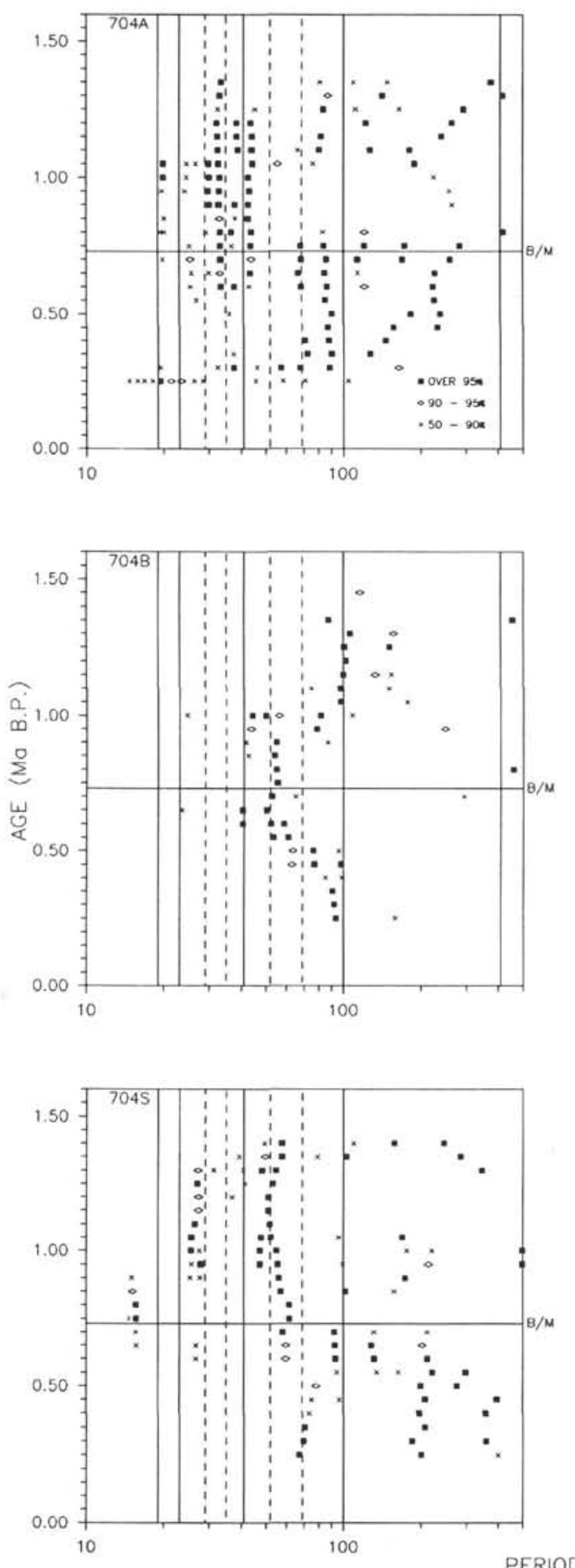

Carbonate Content
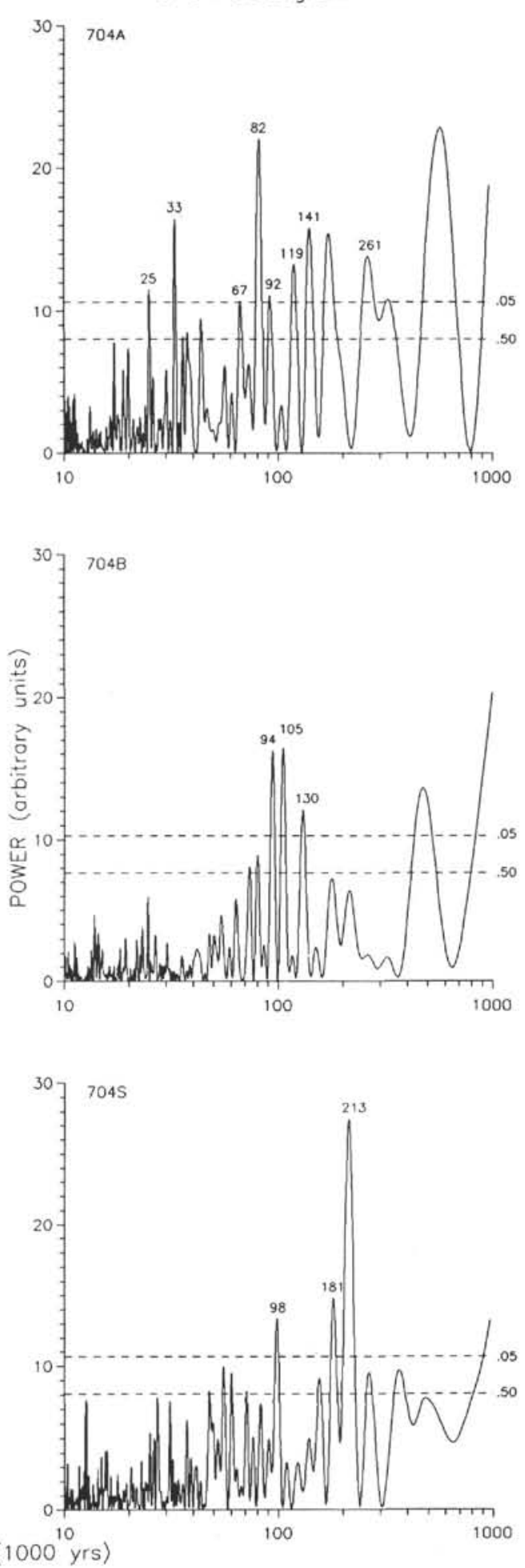

Figure 20. Lomb-Scargle $500,000 \mathrm{yr}$ window evolutive periodograms (left) compared to the Lomb-Scargle periodograms for the whole of the Quaternary (right) for the carbonate content in Holes 704A and 704B and the Site 704 composite section (704S). The peaks in the evolutive spectra are divided into three groups, based on their amplitude and level of significance. A detailed discussion is contained in the text. 